San Jose State University

SJSU ScholarWorks

Master's Theses

Master's Theses and Graduate Research

Spring 2019

\title{
A Spatial Optimization Model for Resource Allocation for Wildfire Suppression and Resident Evacuation
}

Siqiong Zhou

San Jose State University

Follow this and additional works at: https://scholarworks.sjsu.edu/etd_theses

\section{Recommended Citation}

Zhou, Siqiong, "A Spatial Optimization Model for Resource Allocation for Wildfire Suppression and Resident Evacuation" (2019). Master's Theses. 5022.

DOI: https://doi.org/10.31979/etd.x8dn-588y

https://scholarworks.sjsu.edu/etd_theses/5022

This Thesis is brought to you for free and open access by the Master's Theses and Graduate Research at SJSU ScholarWorks. It has been accepted for inclusion in Master's Theses by an authorized administrator of SJSU ScholarWorks. For more information, please contact scholarworks@sjsu.edu. 


\title{
A SPATIAL OPTIMIZATION MODEL FOR RESOURCE ALLOCATION FOR WILDFIRE SUPPRESSION AND RESIDENT EVACUATION
}

\author{
A Thesis \\ Presented to \\ The Faculty of the Department of Industrial and Systems Engineering \\ San José State University \\ In Partial Fulfillment \\ of the Requirements for the Degree \\ Master of Science
}

by

Siqiong Zhou

May 2019 
(C) 2019

Siqiong Zhou

ALL RIGHTS RESERVED 
The Designated Thesis Committee Approves the Thesis Titled

A SPATIAL OPTIMIZATION MODEL FOR RESOURCE ALLOCATION FOR WILDFIRE SUPPRESSION AND RESIDENT EVACUATION

by

Siqiong Zhou

APPROVED FOR THE DEPARTMENT OF INDUSTRIAL AND SYSTEMS ENGINEERING

SAN JOSÉ STATE UNIVERSITY

May 2019

Ayca Erdogan, Ph.D.

Jacob Tsao, Ph.D.

Yasser Dessouky, Ph.D.
Department of Industrial and Systems Engineering

Department of Industrial and Systems Engineering

Department of Industrial and Systems Engineering 


\begin{abstract}
A SPATIAL OPTIMIZATION MODEL FOR RESOURCE ALLOCATION FOR WILDFIRE SUPPRESSION AND RESIDENT EVACUATION
\end{abstract}

by Siqiong Zhou

Wildland-urban interface wildfires have been a significant threat in many countries. This thesis presents an integer two-stage stochastic goal programming model for comprehensive, efficient response to wildfire including firefighting resource allocation and resident evacuation. In contrast to other natural disasters, the progression of wildfires depends on not only the probabilistic fire spread scenarios but also decisions made during firefighting. The proposed model optimizes the resource preparations before the fire starts and resource allocation decisions during the fire event. This model takes into account different wildfire spread scenarios and their impact on high-risk areas. The two objectives considered are minimizing the total cost of operations and property loss and minimizing the number of people at risk to be evacuated. A case study based on Santa Clara County in California, United States of America, is presented to demonstrate the model performance. Quantitative experiments show that this model can help to find efficient solutions by considering a trade-off between two objectives, and varying cell size based on scenarios reduces problem dimension and improves solution time. 


\section{ACKNOWLEDGMENTS}

The completion of this thesis is a result of the support of many people.

First, I would like to express my deep and sincere gratitude to Prof. Ayca Erdogan, my thesis advisor. For many times, I felt lost in choosing a suitable direction to continue with my thesis and I realized that challenges came out one after another. Prof. Erdogan always listened to my ideas patiently and figured out key issues. Even if sometimes we touched to an unfamiliar field to both of us, Prof. Erdogan encouraged me to keep reading advanced papers and try to solve problems independently. All her advising and encouragement made me move ahead and keep growing as a beginner in research.

Second, I would like to thank Prof. Jacob Tsao, who gave me a lot of useful suggestions about career development and academic direction. In addition, Prof. Tsao made me more confident in myself through his encouragements.

Also, I want to thank Prof. Yasser Dessouky, who is an excellent lecturer and taught me systematic thinking in his class. I was encouraged by his lecture to start with this thesis.

I also would like to thank Dee King Raub from Santa Clara County Fire Department for providing valuable information of WUI wildfire containment efforts.

Lastly, I would like to thank my husband, Yu Ni. When I felt confused about the uncertain future, he always stands by me and encourages me to make efforts toward my career goal. It's impossible to finish this thesis without his continued support. Also, thanks Hongyao Ma and Fenfei Guo for their encouragement on my research work. 


\section{TABLE OF CONTENTS}

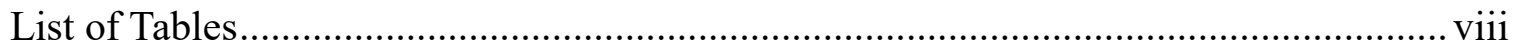

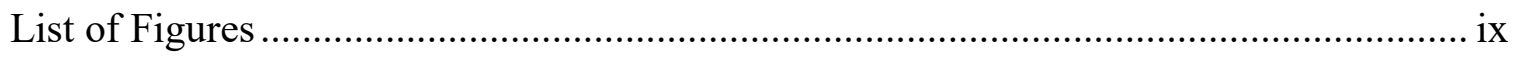

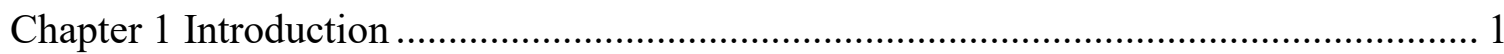

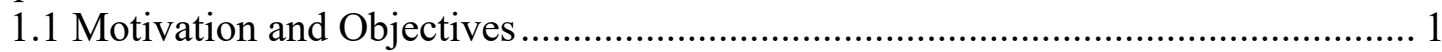

1.2 Challenges of Wildfire Management Modeling .................................................... 1

1.3 Brief Review on Relevant Methodology …………....................................... 2

1.3.1 Stochastic programming ..................................................................... 2

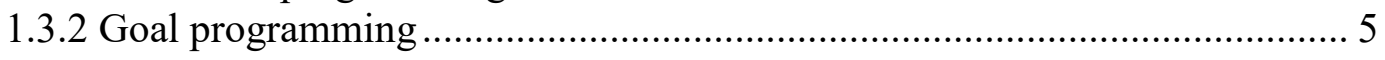

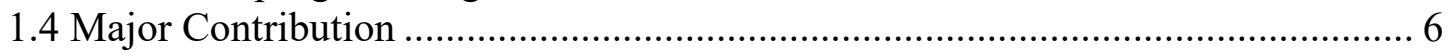

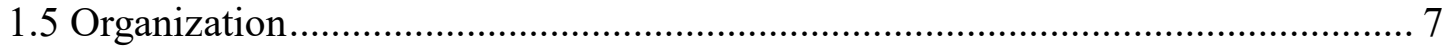

Chapter 2 A Spatial Optimization Model for Resource Allocation for Wildfire

Suppression and Resident Evacuation.......................................................... 8

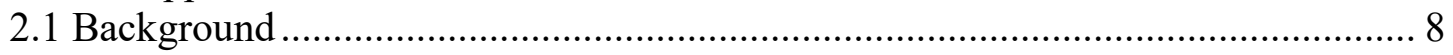

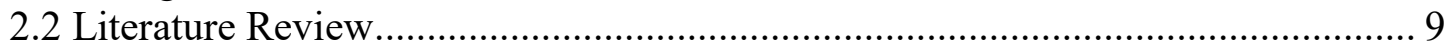

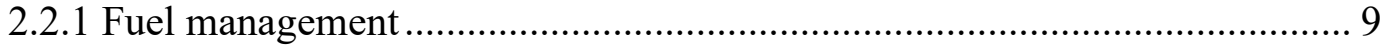

2.2.2 Resource allocation and cost minimization in wildfires ............................. 10

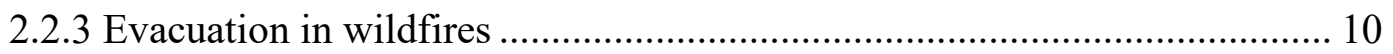

2.2.4 Disaster response with multiple goals........................................................11

2.2.5 Cooperation in wildfire response ............................................................11

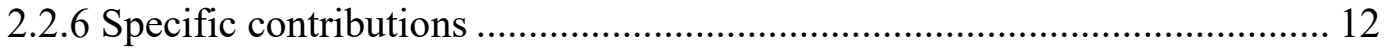

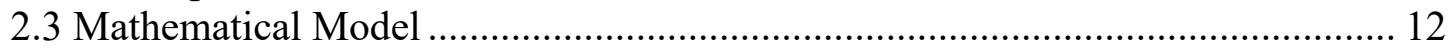

2.3.1 Model assumptions and data sources .......................................................... 12

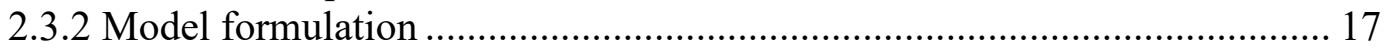

2.3.3 Model Demonstration: A Simple Computational Experiment..................... 22

2.3.4 Solution Approach ............................................................................ 25

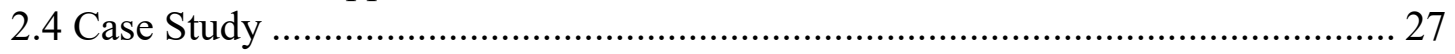

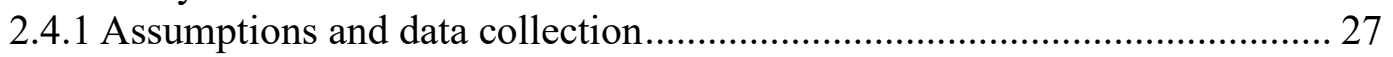

2.4.1.1 Budget ........................................................................................... 27

2.4.1.2 Fire spread in scenarios................................................................ 27

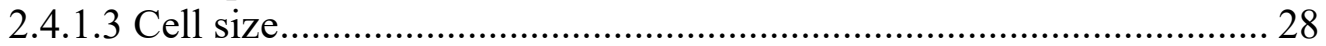

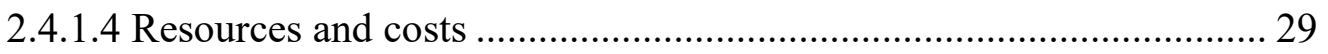

2.4.1.5 Fire containment process and resource availability ............................. 34

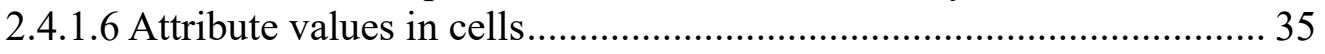

2.4.1.7 Ignition point and cell initialization.................................................. 39

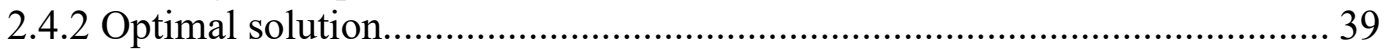

2.4.2.1 Single objective models ………..................................................... 40

2.4.2.2 Two-objective model.......................................................................... 42 
2.4.3 Computational experiments .............................................................. 47

2.4.3.1 Experiments with varied priorities............................................. 47

2.4.3.2 Experiments with varied goal values ............................................ 48

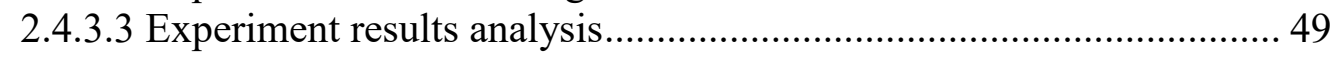

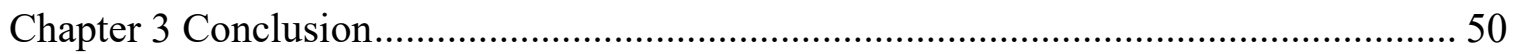

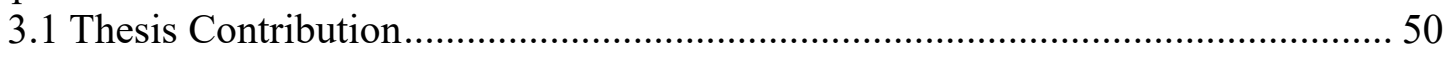

3.2 Limitation and Future Direction .............................................................. 51

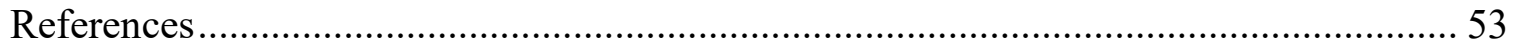




\section{LIST OF TABLES}

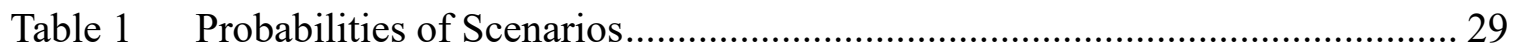

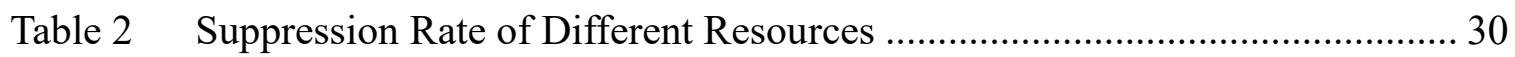

Table 3 Set-Up Cost of An Additional Engine in Different Stations ........................... 32

Table 4 Distances to Fire for Local Stations ............................................................. 32

Table 5 Distances to Fire for Nonlocal Resources .................................................... 32

Table 6 Operation Costs for Nonlocal Resources ...................................................... 32

Table 7 Operation Costs for Local Resources............................................................ 33

Table 8 Capacities of Engine Resource in Fire Station................................................ 36

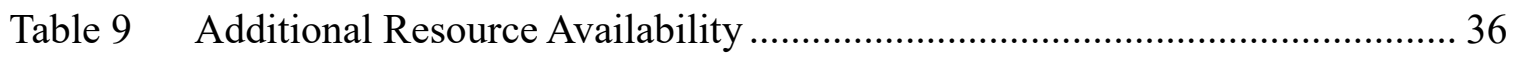

Table 10 First Stage Decision Comparison of Single-Objective Models ...................... 42

Table 11 Resource Preparation and Allocation Results in Two Selected Scenarios ...... 44

Table 12 Computational Experiments Result with G1=1408 and G2=88.13M............ 48

Table 13 Computational Experiments Result with $\mathrm{P} 1=0.9$ and $\mathrm{P} 2=0.1 \ldots \ldots \ldots \ldots \ldots \ldots \ldots \ldots . . .49$ 


\section{LIST OF FIGURES}

Fig. 1. Scenario tree with 5 scenarios in a two-stage stochastic problem................. 3

Fig. 2. Scenario tree with 8 scenarios in a four-stage stochastic problem................ 4

Fig. 3. Flowchart to two-stage wildfire containment problem.............................. 14

Fig. 4. Cell definitions which affect fire spread in different cases where (a) upwind cells in west wind scenario (b) adjacent cells in west wind scenario (c) upwind cells in northwest wind scenario (d) adjacent cells in northwest wind scenario.

Fig. 5. Parameters for cells (a) cell indexes (b) evacuation percentage in each cell (c) population density in each cell (d) land value of each cell.

Fig. 6. Result of single objective experiment with 4 by 4 cells. 24

Fig. 7. Fire preparation and suppression process in the case of Santa Clara County.34

Fig. 8. Geographic areas expressed by cells (a) the fire spread 4 chains per hour and cell size is 24 chains (b) the fire spread 36 chains per hour and cell size is 216 chains.

Fig. 9. Population and property values (million) in each cell (a) slow fire scenario, low population density (b) extremely fast fire scenario, high population density.

Fig. 10. Fire spread process comparison of different single-objective models in $\omega 24$.

Fig. 11. Cell conditions in two selected scenarios. 45 


\section{CHAPTER 1 \\ INTRODUCTION}

\subsection{Motivation and Objectives}

Wildfires in the urban-wildland interface (WUI) have been severe threats to human beings and wildlife. The state of California has a significant number of lands covered by forests and grassland, which are close to populated areas. In recent years, several disastrous wildfires in both Northern California and Southern California have led to a significant number of deaths and economic losses.

The main objective of this thesis is modeling and solving the problem of wildfire preparation and response in a WUI area. Detailed objectives for the model are minimizing residents at risk, property losses, and fire containment cost.

\subsection{Challenges of Wildfire Management Modeling}

The challenges of modeling wildfire management problem are led by the uncertainty of fire size and the dynamic process of fire containment. Due to several factors, wildfire may spread with an unpredictable speed towards different directions. A reasonable mathematical model should consider possible fire scenarios with different rates and directions. However, even if the initial condition of the fire becomes known right after a fire breaks out, firefighters' activities will keep affecting the fire spread, which makes the problem modeling more complicated. In addition, in some rapid-fire cases, fire containment resources may be insufficient for initial response, which leads to another challenge of making plans for fire containment. 


\subsection{Brief Review on Relevant Methodology}

\subsubsection{Stochastic programming}

Stochastic programming is an optimization method to model and solve problems with uncertainty. Uncertainty is caused by random events and it is reflected by random parameters in a stochastic problem. Random parameters represent the undetermined inputs to the optimization problem, and these random parameters may lead the problem to many different solution directions. The importance of random outcomes from experiments is shown as their effects on random parameters, not how they are defined (Birge \& Louveaux, 2011). For example, in the problem of wildfire management, wind speed is shown as the effect to fire spread speed. Different wind speeds will produce varied fire spread outcomes such as a fire with slow spread or rapid spread. However, wind speeds don't need to be defined very accurately; they are important only as a key factor to influence fire spread rate, which can be modeled as a random parameter.

Generally, decision making problems with uncertainty have two types of decisions. The first type of decision, called first stage decisions, is made before the uncertainty is revealed, i.e. random parameters are still undetermined. This period before uncertainty is called the first stage. The second type of decision, called second stage decisions, can be made after the uncertainty is eliminated (observed) and random parameters are determined (revealed). The corresponding period without the uncertainty is the second stage (Birge \& Louveaux, 2011). Since uncertainty is reflected by random parameters in stochastic problems, different directions (outcomes) led by those random parameters 
contribute to different scenarios. In general, these different scenarios do not occur with equal probability; thus, probability distribution of scenarios should be estimated.

Two-stage stochastic programming is a simple form of stochastic programming problem in which uncertainty occurs at only one point in time. Fig. 1 shows a scenario tree that decisions in two stages (before and after uncertainty) lead to different scenarios.

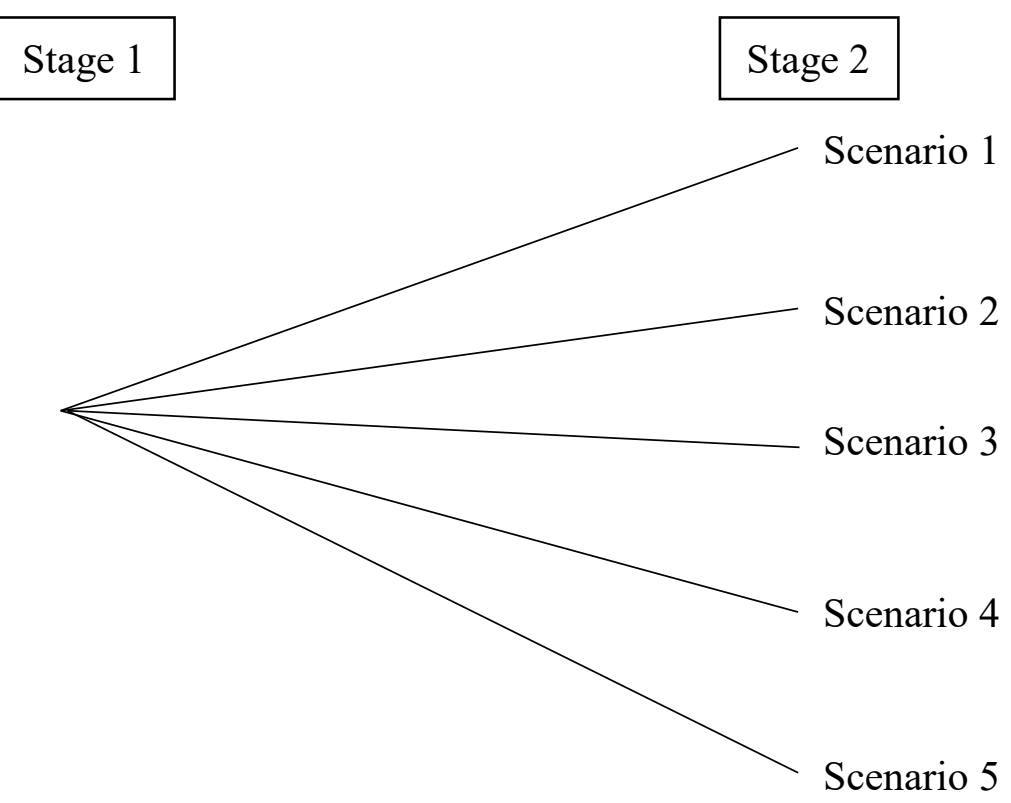

Fig. 1. Scenario tree with 5 scenarios in a two-stage stochastic problem.

When uncertainty has effects in different periods in the problem, the problem becomes a multi-stage stochastic problem. Fig. 2 shows a scenario tree in which decisions at different periods contribute to different scenarios in a four-stage stochastic problem. 


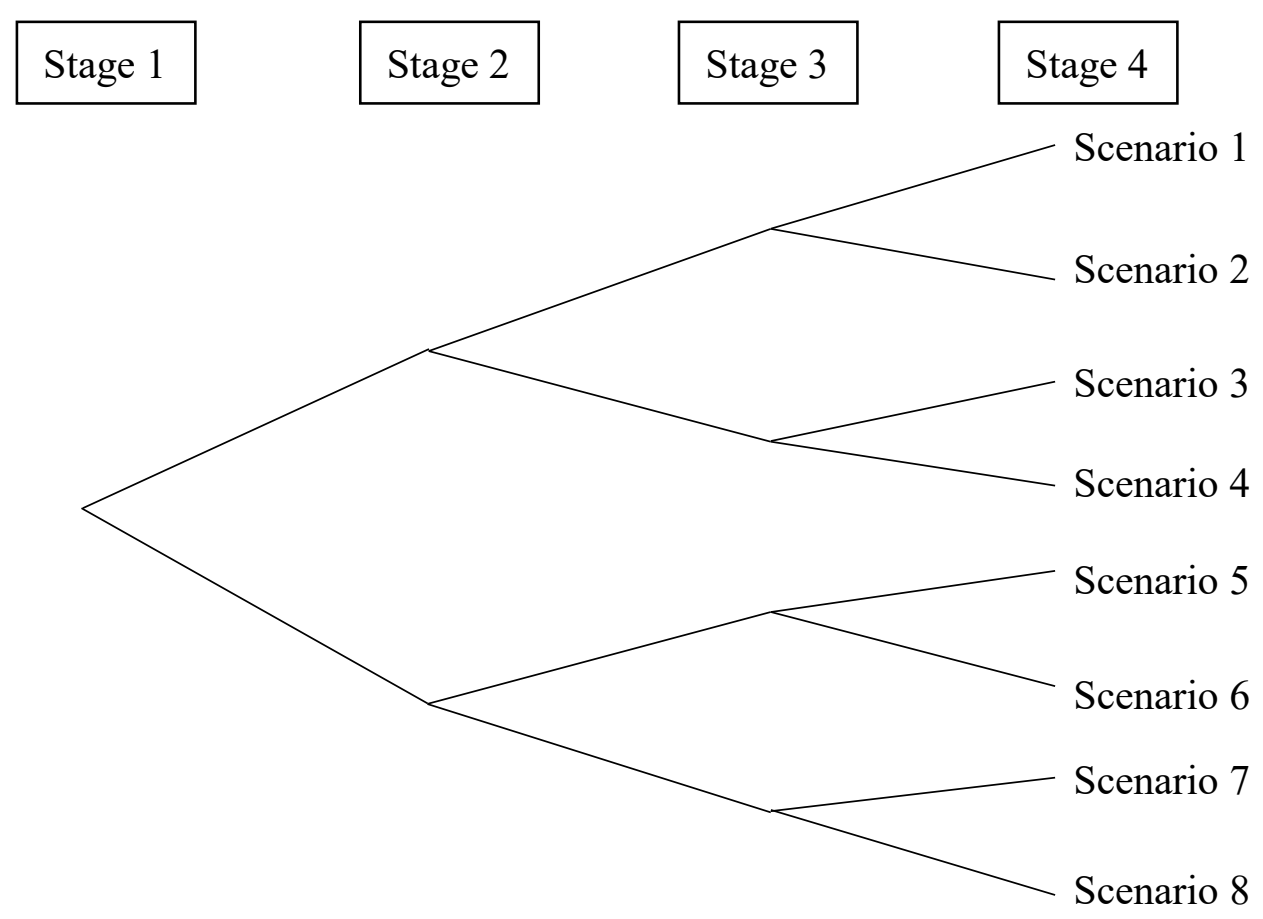

Fig. 2. Scenario tree with 8 scenarios in a four-stage stochastic problem.

Since the optimal solution is highly dependent on the uncertainty in the problem, the way to find solutions to a stochastic problem also depends on whether the uncertainty is modeled as deterministic or not. The optimal solution to a stochastic problem should be a solution which considers all possible scenarios. However, because of uncertainties, it is impossible to find a solution which is always the best choice under all of the circumstances. In the case of a deterministic problem, which means that information about uncertainties is perfect, the optimal solution can be found as the expected value of the solutions to each scenario problem. In the case of a stochastic programming problem, in which information about uncertainties is not perfect, the optimal solution will be found by a model that considers all possibilities. Uncertainties are reflected in the formulation using different parameter values in each scenario. 


\subsubsection{Goal programming}

Goal programming is used to solve problems with multiple and conflicting objectives by setting goals for objective functions and looking for solutions to optimize deviations from these goals (Schniederjans, 1984). Goal programming is also a relatively simple method to solve practical multi-objective problems like wildfire containment problems which require fast solutions. With the goal programming method, Pareto efficiency can be achieved as long as no other solution can improve one of the objectives without making other objectives worse.

Goal programming technique works by removing original objective functions to constraints and setting a new objective function of optimizing, i.e. minimizing, deviations from goals. How to choose suitable goals for each objective function is usually an important issue in goal programming.

To apply goal programming, priorities should be set for each objective function (Schniederjans, 1984). In some cases, priority values are available from experience or results from experiments. Then, a priority value will be given to each corresponding objective function. However, in most real cases, it is hard to know the exact priority value for each objective compared to others. In this condition, goal programming only requires for a priority ordering to objectives, and the objective with higher importance is assumed with a much larger priority value compared to other objectives.

When solving a multi-objective problem with goal programming, the actual process is searching solutions to meet requirements of all the objective functions in the order of their priorities. A solution satisfying the highest priority objective function will be found 
first, and then will be checked if it can also satisfy the rest of the objective functions. If a solution can meet the goal of high priority objectives while not making the low priority objectives worse, the solution will be the optimal one.

The essence of solving a problem with goal programming is looking for tradeoffs among objectives, especially in cases of inaccurate priorities. Goal programming produces various solutions in different settings of goals and priorities to give decision makers a reference when they need to make a decision in a multi-objective problem.

\subsection{Major Contribution}

In this thesis, a mathematical optimization model is developed for management of WUI wildfires, which first, minimizes the number of people at risk in the high-risk areas and second, minimizes the total cost of fire containment and property losses. The model optimizes the resource allocation decisions given limited capacity and availability while taking into account possible wildfire spread scenarios. Scenarios in the model are based on fire spread direction and speed, which are caused by different wind directions and strength. In the proposed model, number of decision variables are kept constant in each scenario by developing a new approach for geographic area representation, so that efficient solutions can be found to highly comprehensive realistic WUI wildfire problems with varying area sites in different scenarios. Solutions to the model, which show the trade-off between objectives, can help decision makers to make choices based on the actual situations they might be facing. 


\subsection{Organization}

In Chapter 2, a spatial optimization model for resource allocation for wildfire suppression and resident evacuation is presented. The chapter is organized as follows: Section 2.1 introduces the background of wildfire management problem. Section 2.2 includes relevant literature on wildfire preparedness and response. Section 2.3 presents the model assumptions, data sources, the stochastic goal programming model and a simple computational experiment. Section 2.4 demonstrates a case study from Santa Clara County. In Chapter 3, conclusions are summarized. 


\section{CHAPTER 2}

\section{A SPATIAL OPTIMIZATION MODEL FOR RESOURCE ALLOCATION FOR WILDFIRE SUPPRESSION AND RESIDENT EVACUATION}

\subsection{Background}

Wildfire management is a challenging and ongoing problem. Although considerable effort has been invested in preventing wildfires, disastrous wildfires still occur every year worldwide. Over the past few years, the WUI wildfires have become greater threats in the United States, Australia, and Portugal. In 2017, wildfires in both North and South California led to losses of more than 10 billion US dollars (Yan, 2017). According to a report from California Department of Forestry and Fire Protection (CAL FIRE), the October 2017 Northern California wildfires, including more than 250 wildfires, resulted in 43 fatalities and widespread evacuations of more than 100,000 people (CAL FIRE, 2017). These fires burned over 245,000 acres, and at least 11,000 firefighters participated in fire containment. The December 2017 Thomas Fire in Southern California charred 281,893 acres, destroyed more than 1,300 structures, and forced over 100,000 people to evacuate (CAL FIRE, 2018). As of December 2018, the Camp Fire, which started on November $8^{\text {th }}, 2018$ in North California and caused 86 civilian fatalities, was the deadliest wildfire in modern California history (CAL FIRE, 2018). All these fires were typical WUI wildfires. Unlike wildfires in wildland, WUI wildfires threaten both the ecosystem and the communities.

According to the wildfire paradox, most wildfires could be controlled by a variety of regular suppression measures, while the remaining wildfires could become disastrous (Calkin, Cohen, Finney, \& Thompson, 2014). Since it is not possible to eliminate the 
occurrence of wildfires, developing effective strategies to prevent the fires from becoming catastrophic is essential. The critical challenge is the uncertainty in fire spread speed and direction. This information becomes observable after the fire breaks out. Even the original size and spread speed are immediately available after a fire breaks out, making a detailed containment plan is still challenging. In contrast to other natural disasters which usually happen at a particular time point and are followed by relief efforts, wildfires keep expanding unless proper and sufficient intervention plans are put into action. These actions involve both containment efforts and evacuation of residents. Also, resources are often limited to execute all the necessary actions. Thus, the prioritization of efforts in different wildfire regions becomes crucial.

\subsection{Literature Review}

Previous modeling efforts have considered different aspects of wildfire management, including developing strategies for fuel management, finding action plans while minimizing costs during fire suppression, and planning for evacuation.

\subsubsection{Fuel management}

One of the main factors that affects the spreading of wildfire is the characteristics of the land. In order to reduce the risks of potential wildfires, preventive actions, often called "fuel management," such as removing live and dead vegetation can be utilized. Minas, Hearne, and Martell presented several models for fuel management problems to reduce wildfire effects (Minas, Hearne, \& Martell, 2014) and prepare for fire suppression (Minas, Hearne, \& Martell, 2015). Rashidi, Medal, Gordon, Grala, and Varner proposed a model to evaluate the worst-case scenario in a specific wildfire (Rashidi, Medal, Gordon, 
Grala, \& Varner, 2017). These models take into account terrains and preventative actions. However, a model which could take into account resource preparation, show the process of fire spreading, and consider the effects of the response process is still needed.

\subsubsection{Resource allocation and cost minimization in wildfires}

Most of the operations management literature includes operations research models for optimal resource allocation with the objective of minimizing costs. These models use linear programming or stochastic programming to optimize resource allocation decisions. For a single fire, Donovan and Rideout built an integer programming model to minimize the sum of suppression cost, preparation cost, and damage cost by optimizing resource allocation (Donovan \& Rideout, 2003). For multiple fires on the same day, Hu and Ntaimo presented a stochastic optimization model to manage fire initial attack response and a simulation model for the suppression process. (Hu \& Ntaimo, 2009). Based on historical data, Arrubla, Ntaimo, and Stripling set up an integer programming model to plan initial responses (Arrubla, Ntaimo, \& Stripling, 2014).

\subsubsection{Evacuation in wildfires}

Even though finding the actions that minimize operational costs is important, saving lives is more critical during a wildfire event. During WUI fires, saving lives within a minimal amount of time is a great challenge. Cova et al. (2005) presented methods for efficient evacuation such as setting evacuation trigger criteria based on a fire spread model using a geographical information system (Cova, Dennison, \& Kim, 2005). Li et al. (2015) also proposed setting evacuation alerts based on trigger modeling ( $\mathrm{Li}, \mathrm{Cova}, \&$ Dennison, 2015). These models mainly focus on initial response. 


\subsubsection{Disaster response with multiple goals}

Firefighting and resident evacuation influence each other. They are usually planned by the same fire department or emergency operations center as a multi-goal task. It has been a common objective to achieve multiple goals in wildfire management similar to management of all kinds of disaster response. Zhan and Liu built a multi-objective stochastic programming model that minimizes both travel time and proportion of unmet demand to disaster response (Zhan \& Liu, 2011). This model handles disasters occurring in a specific location and timing such as earthquakes and hurricanes. However, wildfires differ from earthquakes and hurricanes since they would keep spreading if no actions are taken, and firefighting interventions can affect the fire spread process significantly.

\subsubsection{Cooperation in wildfire response}

Most wildfires can be controlled by local resources (Southwest Coordination Center, 2004), but there are still a few disastrous wildfires that require the cooperation of teams from different counties, states or even countries. Usually, local fire-fighting resources would respond to suppress the initial fire attack, and more nonlocal resources would become available for the response if a fire keeps spreading. Different teams from various areas usually have agreements and plans. For example, the California Fire Service and Rescue Emergency Mutual Aid Plan was adopted to provide a systematic and efficient response when a disaster happens (California Governor's Office of Emergency Services, 2014). 


\subsubsection{Specific contributions}

This thesis presents a two-stage stochastic integer goal programming model which focuses on optimizing the resource allocation considering different wildfire scenarios while minimizing both the number of people in danger and the total cost of fire suppression and land losses. In this model, decisions of containment and evacuation are

made simultaneously so that they can be more efficient and can better reflect reality. As urban areas continue expanding and fire risks in different seasons differ, decisions of on-duty resources scheduled in each fire station need to be made in advance to prepare for possible wildfires. Unlike the models mentioned above, population and property density are both critical factors in this model, which affect both containment and evacuation decisions.

\subsection{Mathematical Model}

\subsubsection{Model assumptions and data sources}

The model presented in this thesis aims to identify the number of on-duty resources before a fire happens and make detailed plans for each potential fire scenario. It minimizes the total number of people at risk and the total value of property losses, and consequently, the areas with higher population density will have higher priority. The model determines the additional necessary local resources that should be kept on duty before a fire happens. After a fire initiates, more information about the fire condition is assumed to be gathered, and more local or even nonlocal resources may join fire suppression if needed in addition to on-duty resources. 
Fire suppression is a multi-stage process as different types of resources (local or non-local) become available at different times if a fire is not contained immediately. The model presented in this thesis formulates this multi-stage process as a two-stage stochastic program. Fig. 3 shows the stages of wildfire containment process considered in this model. The decisions in the first stage involve hiring of additional on-duty resources for every station for the fire season that is under consideration. Once a fire starts, it is assumed that the uncertainties about fire spread speed and direction will be revealed. The uncertainty about fire spread speed and direction is incorporated in the model as scenarios with varying probability of occurrences. In the second stage, a detailed fire suppression plan is made for each specific fire scenario. Decisions in this stage include identifying high-risk areas for evacuation and allocating resources by their availability. Resource availability means some of the resources cannot join fire suppression until a specific period. For instance, resources outside of California cannot be allocated to contain the fire in California until the declaration of a state of emergency, which usually happens 24 hours after fire initiation (CAL FIRE, 2004). Since the operation cost of on-duty resources is lower than any other resources, on-duty resources will always be sent first if a fire happens. Similarly, non-local resources will not be considered unless all the available local resources are utilized, or non-local resources are cheaper in some particular condition. 


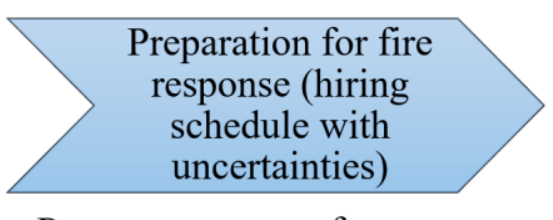

- Prepare resources for initial response. (number of additional on-duty resources)

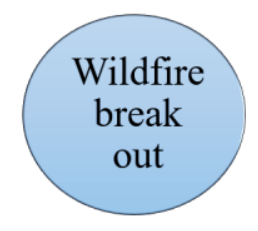

- High risk people evacuation.

- Fire suppression with resources in first decision.

- Allocation of additional local resources and non-local resources.

Fig. 3. Flowchart to two-stage wildfire containment problem.

The model assumes that all the resource allocation decisions are based on the assessment of the fire condition so that more resources are allocated to fires that are substantial. The fire condition affects whether an area is determined as high-risk, completely burned, or treated (under control). By keeping track of fire conditions in each area, resource allocation and evaluation of property losses are determined.

Many uncertainties contribute to different fires such as fuel, wind and season. However, when analyzing a specific location with certain fuel in a specific season, the only uncertainty is caused by the wind. In this model, scenarios are generated considering different wind directions and wind strengths. With the wind direction known, fire spread direction can be estimated. With the wind strength known, fire spread rate can be estimated. In addition, for a specific season, the probability of each scenario can also be estimated by analyzing historical data from a specific region with known fuel type.

In this model, geographical areas are expressed by cells to demonstrate fire spread process and detailed allocation plan. Cell sizes are associated with the fire spread rate and length of each period. In other words, the cell size in a fast fire scenario is larger than the cell size in a slow fire scenario. Varying cell sizes keep the number of decision variables 
constant in different scenarios with different spread speed, which as a result enables us to solve problems with huge geographical areas. For different cell sizes in different fire spread scenarios, cell population density and cell land value can be generated using publicly available data sets. Each cell in the absence of a fire event is considered as a no-risk or safe cell. At the beginning of each possible fire, the initial conditions of cells including the fire-starting point and adjacent cells to the fire-starting point are updated. These initial cell conditions are determined as either high-risk, which means the cell is about to be affected by fire spread or has been partially on fire, or burnt, which means the cell has been fully on fire. In the following periods, suppression efforts based on resource allocation decisions will affect cells' conditions and result in an update.

There are three prerequisites for a cell to be a new high-risk cell: it should have at least one upwind burnt cell currently, it should not have been a burnt cell before, and it should have never been treated before. It is assumed that fire in a specific cell always spreads from upwind cells and can only spread to adjacent cells. The definition of upwind cells and adjacent cells are determined based on wind direction. A cell may have different adjacent cells and upwind cells in different wind directions. For example, Fig. 4 (a) and (b) show that if the wind comes from the west, a cell (analyzed cell shaded in gray) has three adjacent cells on the east side and three upwind cells on the west side so that the fire can spread to this cell from west side cells and possibly spread to east side cells in the next period. Fig. 4 (c) and (d) show that if the wind comes from the northwest, a cell (analyzed cell shaded in gray) has three adjacent cells on the southeast side and three 
upwind cells on the northwest side so that the fire can spread to this cell from northwest side cells and possibly spread to southeast side cells in the next period.

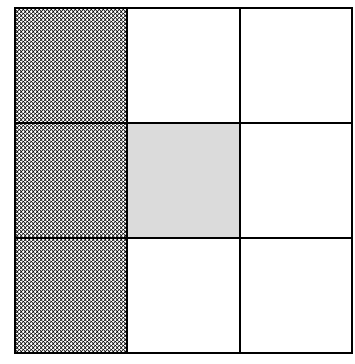

(a)

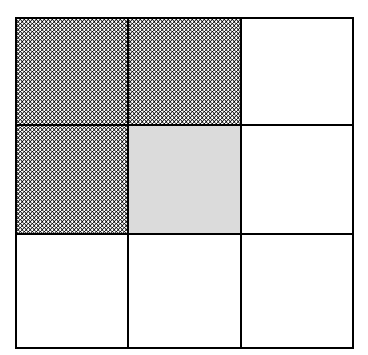

(c)

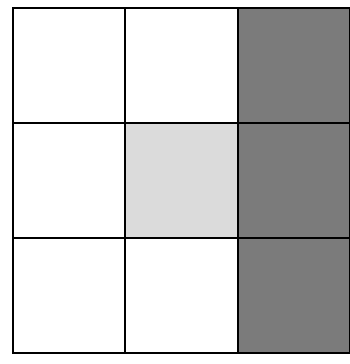

(b)

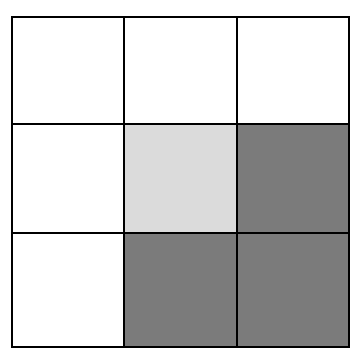

(d)

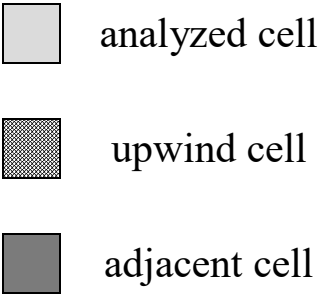

adjacent cell

Fig. 4. Cell definitions which affect fire spread in different cases where (a) upwind cells in west wind scenario (b) adjacent cells in west wind scenario (c) upwind cells in northwest wind scenario (d) adjacent cells in northwest wind scenario.

Average fire spread rates and resources' suppression rates for different types of fuel can be found in the National Wildfire Coordinating Group (NWCG) Fireline Handbook (Incident Operations Standards Working Team [IOSWT], 2004). The published suppression rates consider firefighters' rest time. Thus, in this model, it is assumed that all the allocated resources will keep working at given rates until the fire is fully contained, and no specific rest time is explicitly modeled.

The model assumes that once people are evacuated, they will not go back until the fire ends. Thus, each person will only be counted once when calculating the total number of people at risk. Varying evacuation percentages are used in the model based on different 
fire sizes in order to represent the reality that fire size affects residents' evacuation choices.

\subsubsection{Model formulation}

The model includes the following parameters and decision variables:

Sets:

A Set of cells in consideration, indexed by $\alpha$

I Set of resource types, indexed by $i$

$K \quad$ Set of all local fire stations, indexed by $k$

$L \quad$ Set of all nonlocal resource locations, indexed by $l$

$T \quad$ Set of discrete periods, indexed by $t$

$\Omega \quad$ Set of all fire scenarios, indexed by $\omega$

Parameters:

B $\quad$ Budget

$G S_{i} \quad$ Group size of resource $i$ (required personnel)

$O D_{k i} \quad$ Original on-duty resource $i$ in station $k$

$\operatorname{LIMIT}_{k i} \quad$ Capacity of resource $i$ in station $k$

PCAP Capacity limit of on-duty personnel

$A L R_{\text {kit }} \quad$ Capacity of additional local resource $i$ at station $k$ in period $t(t=1, \ldots, T)$

$N R_{\text {lit }} \quad$ Additional nonlocal capacity of resource $i$ from location $l$ in period $t(t=$ $1, \ldots, T)$

INIT $T_{\alpha}^{\omega} \quad$ Initial high-risk condition at cell $\alpha$ (equal to 1 if the cell is initial high-risk area) 
$R S^{\omega} \quad$ Minimum required suppression rate for each cell in scenarios (chains per hour)

SUP $\quad$ Suppression rate of resource $i$ (chains per hour)

$O D C_{k i} \quad$ Cost of hiring one additional local on-duty resource $i$ at station $k$

$L O R C_{k i} \quad$ Unit operation cost of local on-duty resource $i$ from station $k$

$L R C_{k i} \quad$ Unit Operation cost of local call-for-shift resource $i$ from station $k$

$N R C_{l i} \quad$ Unit operation cost of nonlocal resource $i$ from location $l$

$E V A_{\alpha}^{\omega} \quad$ Evacuation percentage at cell $\alpha$ in scenarios

$D E N_{\alpha}^{\omega} \quad$ Population density at cell $\alpha$ in scenarios (because of different cell sizes)

$V A L U E_{\alpha}^{\omega} \quad$ Property and land value at cell $\alpha$ in scenarios

$p^{\omega} \quad$ Probability of scenario $\omega$

$M^{\omega} \quad \operatorname{Big} M$ in scenarios

Decision variables:

$s_{k i} \quad$ Number of additional local on-duty resources that need to be hired in station $k$

$x_{\text {kiat }}^{\omega} \quad$ Number of local on-duty resources $i$ sent from station $k$ to cell $\alpha$ at period $t$ in scenarios

$y_{\text {kiat }}^{\omega} \quad$ Number of local additional resources $i$ sent from station $k$ to cell $\alpha$ at period $t$ in scenarios

$z_{\text {liat }}^{\omega} \quad$ Number of nonlocal resources $i$ sent from location $l$ to cell $\alpha$ arrived at period $t$ in scenarios 
$\mu_{\alpha t}^{\omega} \quad$ Binary variable defining whether cell $\alpha$ becomes a high-risk area at period $t$ in scenario $\omega$

$\kappa_{\alpha t}^{\omega} \quad$ Binary variable defining whether cell $\alpha$ becomes a fully burnt area at period $t$ in scenario $\omega$

$\varphi_{\alpha t}^{\omega} \quad$ Binary variable defining whether cell $\alpha$ start to be treated at period $t$ in scenario $\omega$

Objective functions:

$\operatorname{Min} O b j_{1}=\sum_{\omega \in \Omega} p^{\omega} \sum_{\alpha \in \mathrm{A}} D E N_{\alpha}^{\omega} E V A_{\alpha}^{\omega} \sum_{t \in T} \mu_{\alpha t}^{\omega}$

$\operatorname{Min} \mathrm{Obj}_{2}=\sum_{k \in K} \sum_{i \in I} O D C_{k i} s_{k i}$

$$
+\sum_{\omega \in \Omega} p^{\omega}\left(\begin{array}{c}
\sum_{k \in K} \sum_{i \in I} \sum_{\alpha \in \mathrm{A}} \sum_{t \in T}\left(x_{k i \alpha t}^{\omega} L O R C_{k i}+y_{k i \alpha t}^{\omega} L R C_{k i}\right)+ \\
\sum_{l \in L} \sum_{i \in I} \sum_{\alpha \in \mathrm{A}} \sum_{t \in T} z_{l i \alpha t}^{\omega} N R C_{l i}+\sum_{\alpha \in \mathrm{A}} \operatorname{VALUE} E_{\alpha}^{\omega} \sum_{t \in T} \kappa_{\alpha t}^{\omega}
\end{array}\right)
$$

Constraints:

$\sum_{k \in K} \sum_{i \in I} O D C_{k i} S_{k i}+\sum_{k \in K} \sum_{i \in I} \sum_{\alpha \in \mathrm{A}} \sum_{t \in T}\left(x_{k i \alpha t}^{\omega} L O R C_{k i}+y_{k i \alpha t}^{\omega} L R C_{k i}\right)+$

$\sum_{l \in L} \sum_{i \in I} \sum_{\alpha \in \mathrm{A}} \sum_{t \in T} z_{l i \alpha t}^{\omega} N R C_{l i} \leq B \quad \forall \omega \in \Omega$

$s_{k i}+O D_{k i} \leq$ LIMIT $_{k i} \quad \forall k \in K, \forall i \in I$

$\sum_{i \in I} \sum_{k \in K} G S_{i}\left(s_{k i}+O D_{k i}\right) \leq P C A P$

$\sum_{\alpha \in A} \sum_{t \in T} x_{k i \alpha t}^{\omega} \leq s_{k i}+O D_{k i} \quad \forall k \in K, \forall i \in I, \forall \omega \in \Omega$

$y_{k i \alpha 0}^{\omega}=0$

$\forall k \in K, \forall i \in I, \forall \alpha \in \mathrm{A}, \forall \omega \in \Omega$

$\sum_{\alpha \in \mathrm{A}} \sum_{t^{\prime} \in(1, t)} y_{k i \alpha t^{\prime}}^{\omega} \leq \operatorname{LIMIT}_{k i}+\sum_{t^{\prime} \in(1, t)} A L R_{k i t^{\prime}}-s_{k i}-O D_{k i}$

$\forall k \in K, \forall i \in I, \forall t \in(1, T), \forall \omega \in \Omega$

$\sum_{\alpha \in \mathrm{A}} \sum_{t^{\prime} \in(1, t)} z_{l i \alpha t^{\prime}}^{\omega} \leq \sum_{t^{\prime} \in(1, t)} N R_{l i t^{\prime}} \quad \forall l \in L, \forall i \in I, \forall \omega \in \Omega, \forall t \in T$ 


$$
\begin{aligned}
& \sum_{i \in I}\left(\sum_{k \in K} x_{k i \alpha t}^{\omega}+\sum_{k \in K} y_{k i \alpha t}^{\omega}+\sum_{l \in L} z_{l i \alpha t}^{\omega}\right) S U P_{i} \geq \varphi_{\alpha t}^{\omega} R S^{\omega} \\
& \forall \alpha \in \mathrm{A}, \forall t \in T, \forall \omega \in \Omega \\
& \mu_{\alpha 0}^{\omega}=I N I T_{\alpha}^{\omega} \\
& \forall \alpha \in \mathrm{A}, \forall \omega \in \Omega \\
& \varphi_{\alpha t}^{\omega} \leq \mu_{\alpha t}^{\omega} \\
& \forall \alpha \in \mathrm{A}, \forall t \in T, \forall \omega \in \Omega \\
& \kappa_{\alpha t}^{\omega}=\mu_{\alpha, t-1}^{\omega}-\varphi_{\alpha, t-1}^{\omega} \\
& \forall \alpha \in \mathrm{A}, \forall t \in(1, T), \forall \omega \in \Omega \\
& M^{\omega}\left(\mu_{\alpha t}^{\omega}+\sum_{0}^{t} \kappa_{\alpha t^{\prime}}^{\omega}+\sum_{0}^{t-1} \varphi_{\alpha t^{\prime}}^{\omega}\right) \geq \sum_{\text {upwind cells of } \alpha} \kappa_{\alpha^{\prime} t}^{\omega} \\
& \forall \alpha \in \mathrm{A}, \forall t \in(1, T), \forall \omega \in \Omega \\
& M^{\omega}\left(1-\mu_{\alpha t}^{\omega}+\sum_{0}^{t} \kappa_{\alpha t^{\prime}}^{\omega}+\sum_{0}^{t-1} \varphi_{\alpha t^{\prime}}^{\omega}\right) \geq 1-\sum_{\text {upwind cells of } \alpha} \kappa_{\alpha^{\prime} t}^{\omega} \\
& \forall \alpha \in \mathrm{A}, \forall t \in(1, T), \forall \omega \in \Omega \\
& M^{\omega}\left(1-\mu_{\alpha t}^{\omega}-\sum_{0}^{t} \kappa_{\alpha t^{\prime}}^{\omega}-\sum_{0}^{t-1} \varphi_{\alpha t^{\prime}}^{\omega}\right) \geq-\sum_{\text {upwind cells of } \alpha} \kappa_{\alpha^{\prime} t}^{\omega} \\
& \forall \alpha \in \mathrm{A}, \forall t \in(1, T), \forall \omega \in \Omega \\
& \sum_{t \in T} \kappa_{\alpha t}^{\omega} \leq 1 \\
& \forall \alpha \in \mathrm{A}, \forall \omega \in \Omega \\
& \sum_{t \in T} \varphi_{\alpha t}^{\omega} \leq 1 \\
& \forall \alpha \in \mathrm{A}, \forall \omega \in \Omega \\
& \sum_{t \in T} \mu_{\alpha t}^{\omega} \leq 1 \\
& \forall \alpha \in \mathrm{A}, \forall \omega \in \Omega \\
& \sum_{t \in T} \kappa_{\alpha t}^{\omega}+\sum_{t \in T} \varphi_{\alpha t}^{\omega} \leq 1 \quad \forall \alpha \in \mathrm{A}, \forall \omega \in \Omega \\
& \sum_{t \in T} \kappa_{\alpha t}^{\omega} \leq \sum_{t \in T} \mu_{\alpha t}^{\omega} \quad \forall \alpha \in \mathrm{A}, \forall \omega \in \Omega \\
& \sum_{t \in T} \varphi_{\alpha t}^{\omega} \leq \sum_{t \in T} \mu_{\alpha t}^{\omega} \quad \forall \alpha \in \mathrm{A}, \forall \omega \in \Omega \\
& \sum_{\alpha \in \mathrm{A}} \sum_{t \in T} \varphi_{\alpha t}^{\omega}+\sum_{\alpha \in \mathrm{A}} \sum_{t \in T} \kappa_{\alpha t}^{\omega}=\sum_{\alpha \in \mathrm{A}} \sum_{t \in T} \mu_{\alpha t}^{\omega} \\
& \forall \omega \in \Omega
\end{aligned}
$$

$s_{k i} \geq 0$

$\forall k \in K, \forall i \in I$

$$
x_{k i \alpha t}^{\omega}, y_{k i \alpha t}^{\omega} \geq 0
$$

$\forall k \in K, \forall i \in I, \forall \alpha \in \mathrm{A}, \forall t \in T, \forall \omega \in \Omega(25)$ 
$z_{\text {liat }}^{\omega} \geq 0$

$\mu_{\alpha t}^{\omega}, \kappa_{\alpha t}^{\omega}, \varphi_{\alpha t}^{\omega} \in\{0,1\}$ $\forall l \in L, \forall i \in I, \forall \alpha \in \mathrm{A}, \forall t \in T, \forall \omega \in \Omega(26)$

$\forall \alpha \in \mathrm{A}, \forall t \in T, \forall \omega \in \Omega$

Objective function (1) minimizes the expected total number of people at-risk who need to be evacuated from high-risk cells over all scenarios. Objective function (2) minimizes the expected total cost of hiring additional on-duty resources, allocating local and non-local resources in scenarios and property losses of burnt cells over all scenarios. The total cost in (2) represents a societal cost since property losses are not incurred by fire departments.

Constraint (3) is the budget constraint which limits the total operation cost of resource preparation and allocation. Constraint (4) limits the number of resources in each station. The sum of on-duty resources in each station including original on-duty resources and additional on-duty resources should meet each station's capacity requirement. Constraint (5) limits the number of on-duty personnel in the current fire department. The total number of on-duty personnel from all the stations should not exceed the department personnel capacity requirements. Constraints (6) to (9) are availability constraints: Constraint (6) ensures that the number of resources to be sent for firefighting cannot exceed the available resource limits. Constraint (7) ensures if a local resource is not on duty, then it is not available at time 0 . Constraint (8) ensures that the number of additional local resources sent to cells must be less than the local resource availability at each time $t$. Constraint (9) ensures that the number of non-local resources sent to cells must be less than the non-local resource availability limitations at each time $t$. Constraint (10) ensures that all of the resources sent to each cell are sufficient to contain the fire, which means 
that the suppression rate in a specific cell should be higher than the required suppression rate. Constraint (11) sets up initial high-risk condition at the beginning of fire for each cell in each scenario. Constraint (12) ensures that only high-risk cells will be treated. Constraint (13) represents the fire spread process. If a cell is a high-risk cell and is not treated in period $t-1$, then it will become a burnt cell in period $t$. Constraints (14) to (16) represent the process of detecting new high-risk cells. Constraint (17) ensures each cell can become a burnt cell for at most one time. Constraint (18) ensures each cell can become a treated cell at most once. Constraint (19) ensures each cell can become a high-risk cell at most once. Constraint (20) means each cell can become a burnt cell or treated cell. If a cell has been a burnt cell, it would never be treated in the future. If it has been a treated cell, it would never become a burnt cell. Constraints (21) to (23) represent the relationships among each cell condition. Constraint (21) means each burnt cell needs to be a high-risk cell previously. Constraint (22) means each treated cell is used to be a high-risk cell. Constraint (23) means each high-risk cell must become a treated cell or a burnt cell at the end.

Constraints (24) to (27) are nonnegativity or binary limitations for decision variables.

\subsubsection{Model Demonstration: A Simple Computational Experiment}

A simple version with 4 by 4 cells is used to test the model with three periods. Each period has a length of one hour. In this experiment, the fire spread rate is 20 chains per hour in each scenario. One of the scenarios has west wind with a probability of 0.8 and the other one has northwest wind with a probability of 0.2 . Fire spread rate doesn't change so that cell size stays the same in each scenario. Thus, evacuation percentages, 
population densities, and land values are fixed in each cell. Cell index and evacuation percentages, population densities, land values are shown in Fig. 5.

\begin{tabular}{|c|c|c|c|}
\hline 0 & 1 & 2 & 3 \\
\hline 4 & 5 & 6 & 7 \\
\hline 8 & 9 & 10 & 11 \\
\hline 12 & 13 & 14 & 15 \\
\hline
\end{tabular}

(a)

\begin{tabular}{|l|l|l|l|}
\hline 0 & 0 & 7 & 9 \\
\hline 0 & 0 & 5 & 6 \\
\hline 0 & 0 & 0 & 2 \\
\hline 0 & 3 & 0 & 3 \\
\hline
\end{tabular}

(c)

\begin{tabular}{|c|c|c|c|}
\hline 0.6 & 0.66 & 0.72 & 0.77 \\
\hline 0.61 & 0.88 & 0.87 & 0.91 \\
\hline 0.78 & 0.95 & 0.96 & 0.63 \\
\hline 0.69 & 0.82 & 0.82 & 0.86 \\
\hline
\end{tabular}

(b)

\begin{tabular}{|c|c|c|c|}
\hline 6 & 7 & 15 & 22 \\
\hline 5 & 5 & 13 & 17 \\
\hline 7 & 4 & 6 & 10 \\
\hline 6 & 10 & 8 & 12 \\
\hline
\end{tabular}

(d)

Fig. 5. Parameters for cells (a) cell indexes (b) evacuation percentage in each cell (c) population density in each cell (d) land value of each cell.

In this experiment, cell 0 and cell 4 are assumed to be the initial high-risk cells in a northwest wind scenario; cell 0 is assumed as the initial high-risk cell in west wind scenario.

To make the suppression process simple, only one station and one kind of resource are considered here. There are no initial on-duty resources in the station. On-duty resource limitation is 3 and the total capacity is 9 . On-duty resources can arrive as early 
as period 0 and other local resources can arrive as early as period 1 . Non-local resources are available in the last period. Suppression rate of each resource is 7 chains per hour.

When ignoring the objective function (2) in this experiment, the problem becomes a single objective problem which only minimizes number of residents at risk. The optimal solution of this simple example is shown in Fig. 6.

$$
\mathrm{S}=3
$$

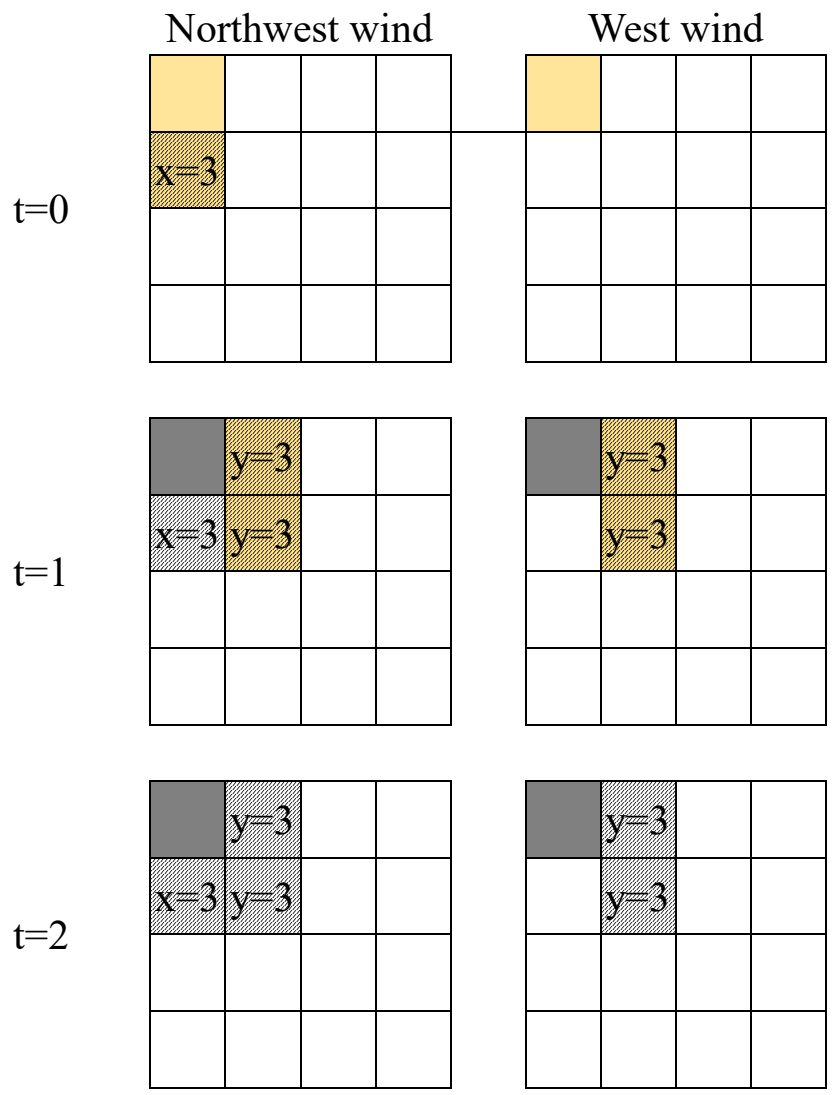

Fig. 6. Result of single objective experiment with 4 by 4 cells.

The results show that the number of on-duty resources required to be hired is 3 . In this experiment, operation costs are not affecting the result since the cost objective function has been removed in the solution process. In the west wind scenario, no on-duty resource is sent in the first period. In this scenario, cell 0 doesn't have residents; thus, 
resources are not sent to initial high-risk cells in period 0 . In period 1, cell 1 and cell 5 still don't have residents, while resources are sent to these two cells since they can prevent populated cells from becoming high risk in the next period by containing fire in current cells. In the northwest wind scenario, even if cell 4 has no resident, resources are still sent there to make sure that the fire won't spread to a very big area which is beyond the containment ability. Because the resource capacity has a limitation of 9 , the model needs to find out a solution that less or equal to 3 treated cells are produced in total.

This simple experiment is used to demonstrate how the model works in updating cell conditions as fire spreads and how decisions are made accordingly when only a single objective is considered.

\subsubsection{Solution Approach}

The solution to this multi-objective model can be found by using goal programming methodology. Several new parameters and variables are needed to solve this problem with goal programming.

Parameters:

$G_{1} \quad$ Goal value of the first objective function

$G_{2} \quad$ Goal value of the second objective function

$P_{1} \quad$ Priority, the importance of the first objective function

$P_{2} \quad$ Priority, the importance of the second objective function

Variables:

$d_{1}^{-} \quad$ Deviation of the first objective function below from $G_{1}$

$d_{1}^{+} \quad$ Deviation of the first objective function above from $G_{1}$ 
$d_{2}^{-} \quad$ Deviation of the second objective function below from $G_{2}$

$d_{2}^{+} \quad$ Deviation of the second objective function above from $G_{2}$

Then the new model is:

$\min \left\{P_{1} d_{1}^{+}+P_{2} d_{2}^{+}\right\}$

$O b j_{1}+d_{1}^{-}-d_{1}^{+}=G_{1}$

$O \mathrm{obj}_{2}+d_{2}^{-}-d_{2}^{+}=G_{2}$

Equations (3) to (27)

Here an assumption is made that the first objective function has a higher priority than the second objective function, i.e., $P_{1} \gg P_{2}$, since human safety is considered to be more important than property safety in reality.

In this model, two objective functions are measured in different units, and the total cost is almost always significantly higher compared to the number of residents at-risk. When these two objective functions are summed up directly, the final solution may have a significant bias. To avoid this issue, the percentage normalization technique is applied here. The percentage normalization method is a simple way to ensure that each objective function can have roughly the same magnitude (Tamiz, Jones, \& Romero, 1998). A normalization constant, $N_{i}$, is needed in this method. The normalization constant is defined as equation (31):

$N_{j}=G_{j} / 100 \quad j=1,2$

Then the updated model is:

$\min \left\{P_{1} \frac{d_{1}^{+}}{N_{1}}+P_{2} \frac{d_{2}^{+}}{N_{2}}\right\}$ 
$O b j_{1}+d_{1}^{-}-d_{1}^{+}=G_{1}$

$\mathrm{Obj}_{2}+d_{2}^{-}-d_{2}^{+}=G_{2}$

Equations (3) to (27)

\subsection{Case Study}

In this section, a case study is presented which considers potential fire scenarios in Santa Clara County, California. Relevant information and data are gathered from the official documents from CAL FIRE, Santa Clara County Fire Department (SCCFD), NWCG, National Wildfire Suppression Association (NWSA), United States Department of Labor (USDL), as well as Google Maps, Zillow Real Estate, and Weather Underground. Details about how data are gathered and used in this case study, along with the assumptions made are explained below.

\subsubsection{Assumptions and data collection}

\subsubsection{Budget}

In most cases, fire departments fight WUI fires without consideration of the budget if a fire event has already occurred. In this model, the budget of fire containment is set as the excess of revenues over expenditures of SCCFD in 2017, which is $\$ 11,501,453$ according to the SCCFD 2017 Annual Report (SCCFD, 2017).

\subsubsection{Fire spread in scenarios}

Fire spread rate is affected by fuel model, slope, fuel moisture, and wind speed. A study by Jin et al. (2015) has shown that typically two fire seasons exist in California and the Santa Ana winds from October to April usually produce the more disastrous fires (Jin et al., 2015). Therefore, in this case, historical weather data from October are used. Based 
on the historical average humidity level in October (The Weather Company, 2018), the reference table from the NWCG (NWCG, 2018), the slope map of Santa Clara County (Graham \& Pike, 1998) and the fuel models map of California (CAL FIRE, The Fire and Resource Assessment Program, 2018), it is assumed that the area considered in this case study has the average characteristics of Santa Clara homogenously. Required suppression rates are assumed to have four levels which are 4 chains per hour, 36 chains per hour, 144 chains per hour, and 324 chains per hour, respectively. The probabilities of each wind direction are calculated as equation (35), in which data are collected from historical wind data in October from 2008 to 2017 (The Weather Company, 2018). $\mathrm{P}\left(\begin{array}{c}\text { wind from a specific direction } \\ \text { with speed in a specific range }\end{array}\right)$

$$
=\frac{\begin{array}{c}
\text { Number of days with wind from } \\
\text { a specific direction with speed in a specific range }
\end{array}}{\text { Total number of days in consideration }}
$$

For each wind range, there is a corresponding fire spread speed level according to NWCG Fireline Handbook (IOSWT, 2004). Probabilities to scenarios with different fire spread direction and fire speed (chains per hour) are shown in Table 1.

\subsubsection{Cell size}

We assume that each period has a length of 6 hours. Accordingly, the size of each cell in the specific scenario is determined as the distance that fire can spread in 6 hours without treatment so that fire's spread speed in scenarios can always be expressed as "one cell per period." For example, when the fire spread rate is four chains per hour, the cell size will be 24 chains. 
Table 1

Probabilities of Scenarios

\begin{tabular}{|c|c|c|c|c|}
\hline $\begin{array}{r}\text { Fire speed } \\
\text { (chains/hour) }\end{array}$ & 4 & 12 & 24 & 36 \\
\hline Wind direction & 0 & 0.003226 & 0 & 0 \\
\hline $\mathrm{NE}$ & 0.003226 & 0 & 0.003226 & 0 \\
\hline $\mathrm{SE}$ & 0.003226 & 0.093548 & 0.048387 & 0.009677 \\
\hline $\mathrm{N}$ & 0.006452 & 0.006452 & 0 & 0 \\
\hline $\mathrm{NW}$ & 0.151612 & 0.477419 & 0.022581 & 0.009677 \\
\hline $\mathrm{S}$ & 0.003226 & 0.016129 & 0.003226 & 0 \\
\hline $\mathrm{SW}$ & 0.006452 & 0.051613 & 0.009677 & 0 \\
\hline $\mathrm{W}$ & 0.009677 & 0.058065 & 0.003226 & 0 \\
\hline
\end{tabular}

\subsubsection{Resources and costs}

Two types of resources are considered in the case study, engine group and hand crew. Since either engine group or hand crew can have different numbers of personnel, which contribute to different suppression speeds, this case study assumes that engine groups may include 1 firefighter, 2 firefighters, 3 firefighters, 4 firefighters or 5 firefighters and hand crews may include 7 firefighters or 20 firefighters based on NWCG Fireline Handbook (IOSWT, 2004). For hardwood fuel, line production rates of both resources are estimated by NWCG (IOSWT, 2004). Detailed suppression rates of different resources are shown in Table 2. 
Table 2

Suppression Rate of Different Resources

\begin{tabular}{|c|c|c|c|c|c|}
\hline $\begin{array}{c}\text { Fire } \\
\text { Behavior } \\
\text { Fuel Model }\end{array}$ & \multicolumn{5}{|c|}{ Construction Rate by Hand Crews in Chains per Person per Hour } \\
\hline \multirow{4}{*}{$\begin{array}{l}\text { Hardwood } \\
\text { Litter }\end{array}$} & \multicolumn{5}{|c|}{2.0} \\
\hline & \multicolumn{5}{|c|}{ Construction Rate by Engine Crews in Chains per Crew per Hour } \\
\hline & $\begin{array}{c}\text { 1-person } \\
\text { crew }\end{array}$ & $\begin{array}{c}\text { 2-person } \\
\text { crew }\end{array}$ & $\begin{array}{c}\text { 3-person } \\
\text { crew }\end{array}$ & $\begin{array}{c}\text { 4-person } \\
\text { crew }\end{array}$ & $\begin{array}{c}\text { 5-person } \\
\text { crew }\end{array}$ \\
\hline & 3 & 7 & 12 & 18 & 22 \\
\hline
\end{tabular}

In this case study, an assumption is that only a single fire starts at period 0 , and all the operational costs are calculated based on this fire location. Resources from the local fire department are considered as local resources. Other resources including in-state resources and out-of-state resources are treated as non-local resources. Costs of containment of the fire include payment for additional on-duty firefighters, on-duty resources operation cost, local call-for-shift resources operation cost and non-local resource operation cost. The set-up cost of an additional on-duty firefighter is assumed as $\$ 5500$ based on the data from the USDL (USDL, 2018). The set-up cost of an additional engine or truck, including preventative maintenance, training and some other indirect costs of fires, is also assumed for each station based on the data from the NWSA (NWSA, 2013). Details of engine resource set-up costs are shown in Table 3.

Operation costs of on-duty resources, local call-for-shift resources, and non-local resources are estimated based on the data from the NWSA (NWSA, 2013), the Pacific Northwest Wildfire Coordinating Group (Pacific Northwest Wildfire Coordinating Group, 
2017) and Google Maps (Google, 2018). The different distances between fire stations and the fire lead to different transportation costs, which finally affect resource assignment priorities. Thus, closer resources will be assigned first. Details of different distances from local stations to fire are shown in Table 4. Since the distances of nonlocal resources are varied from station to station, average distances are assumed for neighbor-county resources, in-state resources, and out-of-state resources, respectively. Details of different nonlocal resources distances are shown in Table 5. The equation of calculating the operational cost to a specific resource is shown in equation (36).

Operational cost $=$ unit traffic cost $\times$ distance +

$$
\text { personnel payment } \times \text { number of people }
$$

In this case, unit traffic cost is assumed as $\$ 270$ per mile. Personnel payment for both call-for-shift local resources and neighbor-county resources are assumed as $\$ 616$. Personnel payment for both in-state resources and out-of-state resources are assumed as \$776. Assumptions to unit traffic cost and personnel payment are made based on the data from the NWSA (NWSA, 2013). Then operational costs for both local resources and nonlocal resources can be calculated as equation (36). Details of operational costs are shown in Table 6 and Table 7. 
Table 3

Set-Up Cost of An Additional Engine in Different Stations

\begin{tabular}{|c|c|c|c|c|c|c|c|c|c|c|c|c|c|c|c|}
\hline Station & 0 & 1 & 2 & 3 & 4 & 5 & 6 & 7 & 8 & 9 & 10 & 11 & 12 & 13 & 14 \\
\hline $\begin{array}{c}\text { Engine } \\
\text { set-up cost (\$) }\end{array}$ & 3256 & 2701 & 1517 & 5735 & 6327 & 5661 & 4070 & 2257 & 2405 & 3737 & 4403 & 3367 & 2849 & 5254 & 3256 \\
\hline
\end{tabular}

Table 4

Distances to Fire for Local Stations

\begin{tabular}{|c|c|c|c|c|c|c|c|c|c|c|c|c|c|c|c|}
\hline Station & 0 & 1 & 2 & 3 & 4 & 5 & 6 & 7 & 8 & 9 & 10 & 11 & 12 & 13 & 14 \\
\hline Distance (mile) & 8.8 & 7.3 & 4.1 & 15.5 & 17.1 & 15.3 & 11 & 6.1 & 6.5 & 10.1 & 11.9 & 9.1 & 7.7 & 14.2 & 8.8 \\
\hline
\end{tabular}

Table 5

Distances to Fire for Nonlocal Resources

\begin{tabular}{|c|c|c|c|}
\hline Resource & Neighbor-county & In-state & Out-of-state \\
\hline Distance (mile) & 25 & 300 & 600 \\
\hline
\end{tabular}

Table 6

Operation Costs for Nonlocal Resources

\begin{tabular}{|c|c|c|c|c|c|c|c|}
\hline Resource i & 0 & 1 & 2 & 3 & 4 & 5 & 6 \\
\hline NRC_i neighbor & 7366 & 7982 & 8598 & 9214 & 9830 & 11062 & 19070 \\
\hline NRC_i in-state & 81776 & 82552 & 83328 & 84104 & 84880 & 11032 & 31520 \\
\hline NRC_i out-of-state & 162776 & 163552 & 164328 & 165104 & 165880 & 12432 & 35520 \\
\hline
\end{tabular}


Table 7

Operation Costs for Local Resources

\begin{tabular}{|c|c|c|c|c|c|c|c|c|c|c|c|c|c|c|c|}
\hline station k & 0 & 1 & 2 & 3 & 4 & 5 & 6 & 7 & 8 & 9 & 10 & 11 & 12 & 13 & 14 \\
\hline LORC_k0 & 2376 & 1971 & 1107 & 4185 & 4617 & 4131 & 2970 & 1647 & 1755 & 2727 & 3213 & 2457 & 2079 & 3834 & 2376 \\
\hline LORC_k1 & 2376 & 1971 & 1107 & 4185 & 4617 & 4131 & 2970 & 1647 & 1755 & 2727 & 3213 & 2457 & 2079 & 3834 & 2376 \\
\hline LORC_k2 & 2376 & 1971 & 1107 & 4185 & 4617 & 4131 & 2970 & 1647 & 1755 & 2727 & 3213 & 2457 & 2079 & 3834 & 2376 \\
\hline LORC_k3 & 2376 & 1971 & 1107 & 4185 & 4617 & 4131 & 2970 & 1647 & 1755 & 2727 & 3213 & 2457 & 2079 & 3834 & 2376 \\
\hline LORC_k4 & 2376 & 1971 & 1107 & 4185 & 4617 & 4131 & 2970 & 1647 & 1755 & 2727 & 3213 & 2457 & 2079 & 3834 & 2376 \\
\hline LORC_k5 & N/A & N/A & N/A & N/A & N/A & N/A & N/A & N/A & N/A & N/A & N/A & N/A & N/A & N/A & 2376 \\
\hline LORC_k6 & N/A & N/A & N/A & N/A & N/A & N/A & N/A & N/A & N/A & N/A & N/A & N/A & N/A & N/A & 2376 \\
\hline LRC_k0 & 2992 & 2587 & 1723 & 4801 & 5233 & 4747 & 3586 & 2263 & 2371 & 3343 & 3829 & 3073 & 2695 & 4450 & 2992 \\
\hline LRC_k1 & 3608 & 3203 & 2339 & 5417 & 5849 & 5363 & 4202 & 2879 & 2987 & 3959 & 4445 & 3689 & 3311 & 5066 & 3608 \\
\hline LRC_k2 & 4224 & 3819 & 2955 & 6033 & 6465 & 5979 & 4818 & 3495 & 3603 & 4575 & 5061 & 4305 & 3927 & 5682 & 4224 \\
\hline LRC_k3 & 4840 & 4435 & 3571 & 6649 & 7081 & 6595 & 5434 & 4111 & 4219 & 5191 & 5677 & 4921 & 4543 & 6298 & 4840 \\
\hline LRC_k4 & 5456 & 5051 & 4187 & 7265 & 7697 & 7211 & 6050 & 4727 & 4835 & 5807 & 6293 & 5537 & 5159 & 6914 & 5456 \\
\hline LRC_k5 & N/A & N/A & N/A & N/A & N/A & N/A & N/A & N/A & N/A & N/A & N/A & N/A & N/A & N/A & 6688 \\
\hline LRC_k6 & N/A & N/A & N/A & N/A & N/A & N/A & N/A & N/A & N/A & N/A & N/A & N/A & N/A & N/A & 14696 \\
\hline
\end{tabular}




\subsubsection{Fire containment process and resource availability}

The working process of this case can be shown as the flowchart in Fig. 7.

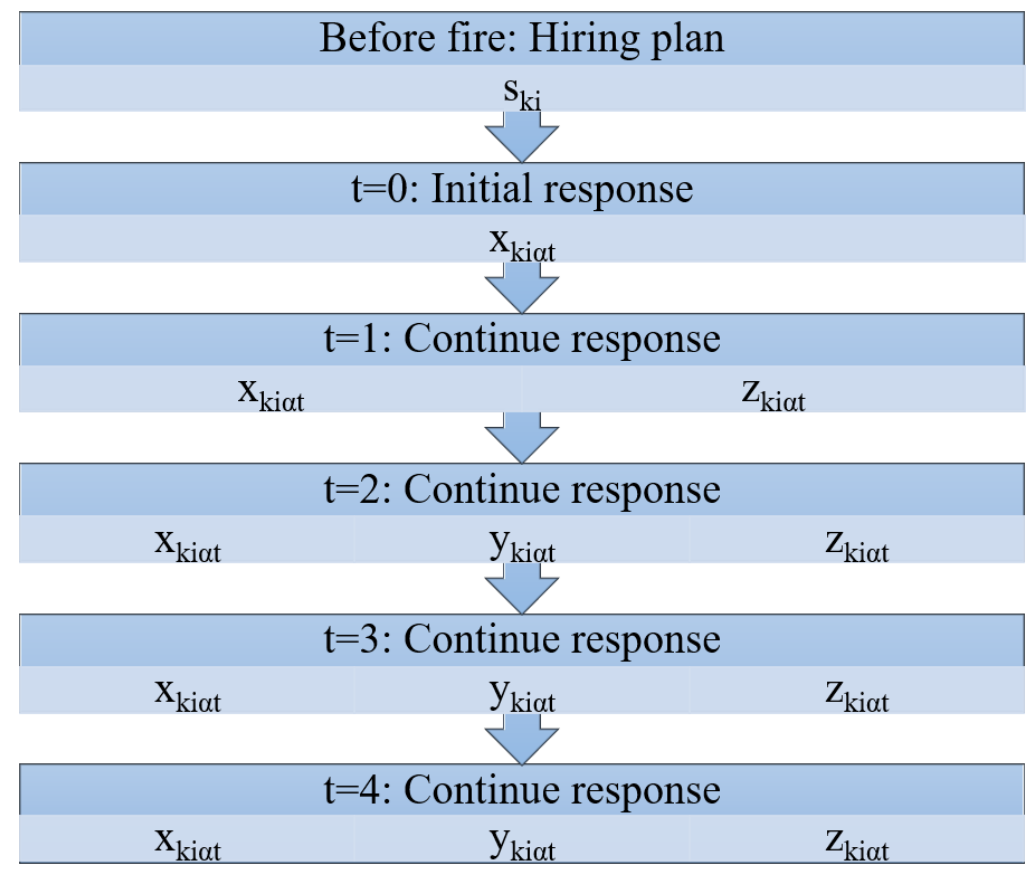

Fig. 7. Fire preparation and suppression process in the case of Santa Clara County.

The first decision before the fire is the number of additional on-duty engine groups and the group size. The capacity of engine resource for each fire station in Santa Clara County is determined according to the information from the SCCFD (SCCFD, 2015). Details of engine capacities in each local fire station are shown in Table 8. In addition to the engine capacities, there is an upper limit of 66 full-time personnel and 25 volunteers in total for the county fire department (SCCFD, 2015). In reality, the number of on-duty resources is also determined by many factors such as urban fires, traffic accident rescue in addition to wildfires. Thus, in this case, an assumption is made that each station has one 3-person engine group on duty due to other considerations. 
After a fire breaks out, it is assumed that engine groups from nearby state fire stations can join containment as early as the second period (after 6 hours), and engine groups from neighbor departments can join containment as early as the third period (after 12 hours). Local hand crews can also come as early as the third period (after 12 hours). Since station 15 and the headquarter of SCCFD have the same location, additional local hand crew resources are assumed to be sent from station 15. More in-state resources can start to contain the fire as early as the fourth period (after 18 hours). Additional out-of-state resources will come after 24 hours. Table 9 shows the detailed additional resource availability. Detailed resource availability is estimated based on a report from the SCCFD (SCCFD, 2017) and CAL FIRE (CAL FIRE, 2004). Response times and capacities of all these resources can be adjusted with more details if a higher accuracy level is required.

\subsubsection{Attribute values in cells}

Fig. 8 shows the geographic areas which are covered in the slow fire and the extremely fast fire scenarios as an example. Geographic information is gathered from Google Maps (Google, 2018). Population and property values for each cell are shown in Fig. 9. The value in the first row of each cell represents the number of residents in specific cell, and the value in the second row of each cell represents the land values of a specific cell. Population densities and property values are estimated based on the cell size and publicly available information such as census data and median housing values. Population densities and property values of wildlands are collected from the result of the census (U.S. Department of Commerce, 2018) and Zillow (Zillow, 2018). 
Table 8

Capacities of Engine Resource in Fire Station

\begin{tabular}{|c|c|c|c|c|c|c|c|c|c|c|c|c|c|c|c|}
\hline station & 0 & 1 & 2 & 3 & 4 & 5 & 6 & 7 & 8 & 9 & 10 & 11 & 12 & 13 & 14 \\
\hline \# of engine & 3 & 1 & 2 & 1 & 3 & 2 & 2 & 2 & 1 & 2 & 1 & 2 & 1 & 2 & 0 \\
\hline
\end{tabular}

Table 9

Additional Resource Availability

\begin{tabular}{|c|c|c|c|c|c|c|c|c|}
\hline \multirow[b]{2}{*}{$\mathrm{t}$} & \multicolumn{2}{|c|}{ Local resources } & \multicolumn{6}{|c|}{ Non-local resources } \\
\hline & $\begin{array}{l}\text { Local } \\
\text { additional } \\
\text { engine crew }\end{array}$ & $\begin{array}{l}\text { Local } \\
\text { additional } \\
\text { hand crew } \\
\text { personnel }\end{array}$ & $\begin{array}{c}\text { Neighbor } \\
\text { CAL FIRE } \\
\text { station engine }\end{array}$ & $\begin{array}{c}\text { Neighbor } \\
\text { Department } \\
\text { station engine }\end{array}$ & $\begin{array}{c}\text { In-state } \\
\text { Additional } \\
\text { hand crew } \\
\text { personnel }\end{array}$ & $\begin{array}{c}\text { In-state } \\
\text { Additional } \\
\text { engine }\end{array}$ & $\begin{array}{l}\text { Out-of-state } \\
\text { Additional } \\
\text { hand crew }\end{array}$ & $\begin{array}{c}\text { Out-of-state } \\
\text { Additional } \\
\text { engine }\end{array}$ \\
\hline 1 & & & 8 & & & & & \\
\hline 2 & & 61 & & 70 & & & & \\
\hline 3 & & & & & 1783 & 229 & & \\
\hline 4 & & & & & 4300 & & 9999 & 9999 \\
\hline
\end{tabular}




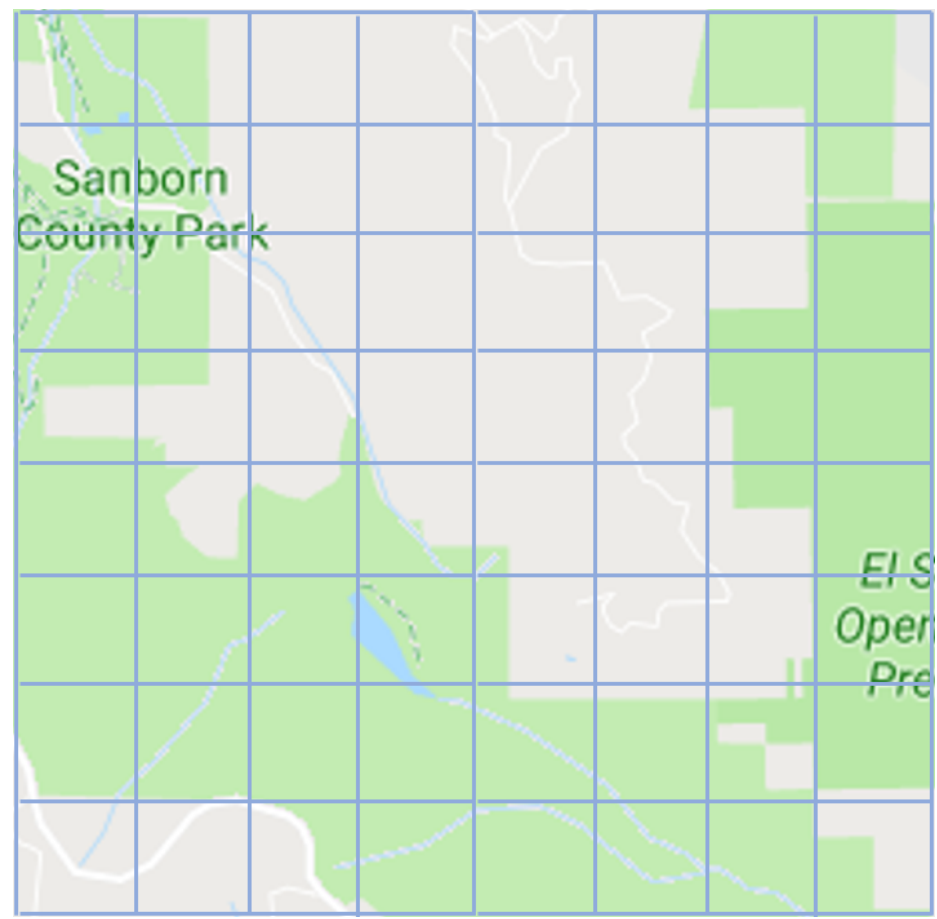

(a)

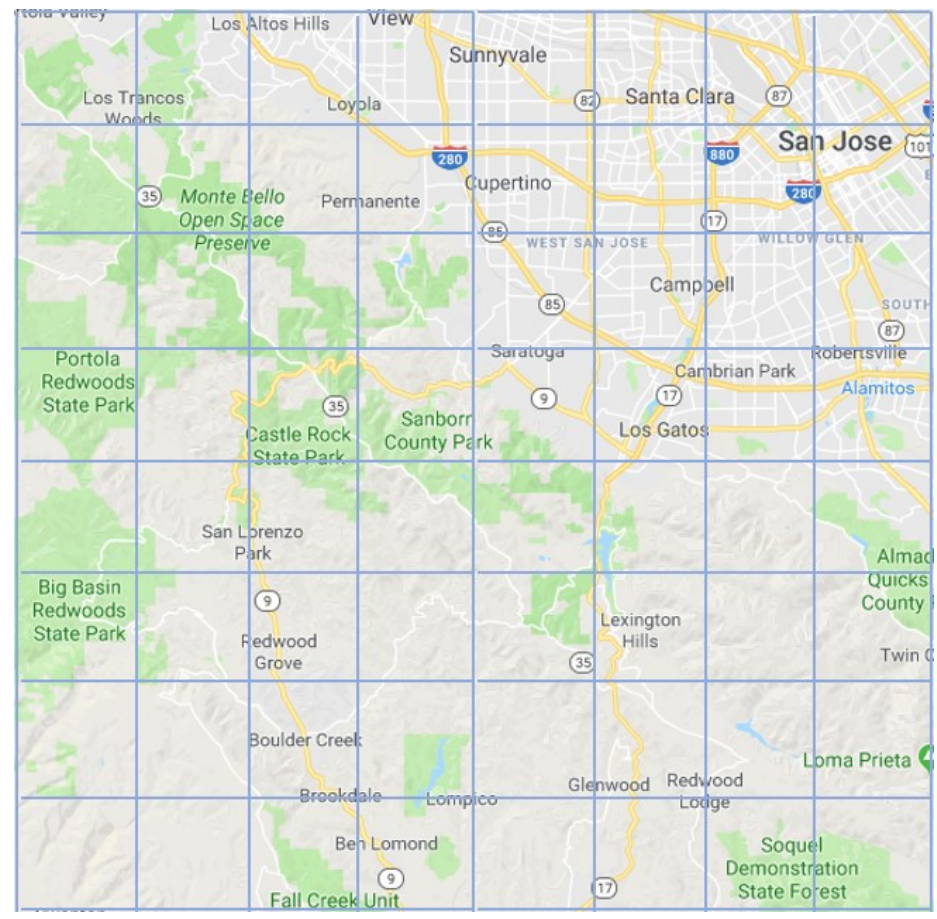

(b)

Fig. 8. Geographic areas expressed by cells (a) the fire spread 4 chains per hour and cell size is 24 chains (b) the fire spread 36 chains per hour and cell size is 216 chains. 


\begin{tabular}{|c|c|c|c|c|c|c|c|}
\hline 2 & 0 & 0 & 0 & 31 & 0 & 0 & 0 \\
2.9 & 0.3 & 0.3 & 0.3 & 57.8 & 0.3 & 0.3 & 0.3 \\
\hline 0 & 2 & 0 & 0 & 36 & 2 & 2 & 2 \\
0.3 & 7.6 & 0.3 & 0.3 & 65.5 & 5.3 & 5.2 & 4.4 \\
\hline 0 & 0 & 18 & 0 & 0 & 2 & 0 & 0 \\
0.3 & 0.3 & 30 & 0.3 & 1 & 4.4 & 0.3 & 0.3 \\
\hline 0 & 0 & 16 & 2 & 0 & 7 & 0 & 0 \\
0.3 & 0.3 & 26.8 & 2.6 & 1 & 21.7 & 0.3 & 0.3 \\
\hline 0 & 5 & 0 & 2 & 0 & 16 & 0 & 0 \\
0.3 & 9.8 & 0.9 & 2.7 & 1 & 19.8 & 0.3 & 0.3 \\
\hline 0 & 0 & 0 & 0 & 5 & 13 & 18 & 0 \\
0.5 & 0.5 & 0.9 & 0.9 & 7.7 & 16 & 17.8 & 0.3 \\
\hline 0 & 0 & 0 & 0 & 0 & 0 & 9 & 2 \\
0.5 & 0.5 & 0.7 & 0.7 & 0.7 & 0.7 & 7.2 & 0.4 \\
\hline 35 & 5 & 7 & 0 & 0 & 0 & 7 & 2 \\
28.8 & 4.6 & 5.8 & 0.3 & 0.3 & 0.3 & 9.6 & 5.7 \\
\hline
\end{tabular}

(a)

\begin{tabular}{|c|c|c|c|c|c|c|c|}
\hline 7630 & 13643 & 13702 & 43830 & 49601 & 48602 & 42549 & 41684 \\
7215 & 13476 & 15224 & 29110 & 23674 & 19833 & 15812 & 15238 \\
\hline 2543 & 15260 & 2760 & 38907 & 41595 & 45143 & 41900 & 41684 \\
2405 & 14430 & 2646 & 27332 & 24012 & 17535 & 15382 & 15238 \\
\hline 954 & 1272 & 636 & 28909 & 23871 & 46485 & 44084 & 41684 \\
902 & 1203 & 601 & 20917 & 17686 & 19080 & 17159 & 15238 \\
\hline 102 & 205 & 307 & 255 & 12312 & 20062 & 36279 & 41684 \\
89 & 178 & 267 & 2587 & 11930 & 14917 & 15158 & 15238 \\
\hline 8 & 15 & 23 & 30 & 2998 & 10031 & 12734 & 20842 \\
22 & 45 & 67 & 89 & 2261 & 7459 & 7499 & 7619 \\
\hline 19 & 67 & 539 & 530 & 1019 & 2038 & 1359 & 699 \\
13 & 28 & 86 & 199 & 521 & 1041 & 694 & 347 \\
\hline 39 & 135 & 2734 & 533 & 487 & 509 & 339 & 170 \\
17 & 56 & 453 & 100 & 92 & 260 & 174 & 87 \\
\hline 38 & 113 & 315 & 2548 & 2659 & 1172 & 170 & 85 \\
13 & 33 & 76 & 515 & 650 & 295 & 87 & 43 \\
\hline
\end{tabular}

(b)

Fig. 9. Population and property values (million) in each cell (a) slow fire scenario, low population density (b) extremely fast fire scenario, high population density. 
Varying evacuation percentages are assumed for different fire scenarios. Evacuation percentages for each cell are assumed as $82 \%, 86 \%, 90 \%, 94 \%$ for slow speed fire, medium speed fire, high-speed fire, extremely high-speed fire respectively based on Paveglio, Prato, Dalenberg, and Venn's study (Paveglio, Prato, Dalenberg, \& Venn, 2014). These estimates may be affected by the average population age in each cell and some other factors however no stratified data are currently available.

\subsubsection{Ignition point and cell initialization}

Historical data of fire locations from CAL FIRE show that some of the locations always have a higher fire risk. For example, the October 2017 Tubbs Fire happened at the same place as the September 1964 C. Hanley Fire, and the two fires also had very similar sizes. Therefore, an assumption can be made that the fires in different scenarios all start from a specific point. However, when there is more than one ignition point, the only differences in this model are scenarios and initial cell conditions, which are easy to achieve by adjusting related parameters. In this case study, it is assumed that a single fire in the center of an area with 64 cells, i.e., the junction of cell 27, 28, 35, 36, starts at the beginning of the first period. However, this model could also be used for cases with multiple fires initiating at different locations at different time points by adjusting to the parameters related to initial high-risk cells.

\subsubsection{Optimal solution}

The model is solved by Gurobi Optimizer 7.5.1 with Anaconda Python 3.6 interface on a Dell XPS 13 - 9350 machine with Intel Core 6th Generation i5-6200U Processor, 
8GB RAM (Gurobi Optimization, 2018). The formulation in this case study included 2,396,265 decision variables and 2,674,739 constraints.

\subsubsection{Single objective models}

The optimal solution to this case can be found easily when only one objective is considered. In this case, there are two single-objective models if either number of residents in danger or total cost is set as objective function. The optimal solution to a single-objective model of minimizing residents at risk is found as 1408 . The optimal solution to a single-objective model of minimizing total cost and property loss is found as $\$ 88,129,615$.

Fig. 10 shows how different objective functions affect fire spread process in selected scenario $\omega 24$. Note that Fig. 10 shows only the partial areas of 64 cells that are involved in selected periods.

Since the objective function of minimizing residents at risk is affected by number of residents in high-risk cells, in period 2, decision is made that available resources are sent to cell $46,51,52$, and 53. In this situation, resources in period 2 are not enough to contain the fire, and cell 54 has the lowest population comparing to the other high-risk cells. As a result, resources are not sent to cell 54. However, the objective function of minimizing total cost and property loss is affected by land value and allocation cost; thus, in period 2 , decision is made that available resources are sent to cell $46,51,53$, and 54 . In this situation, cell 52 has the lowest land value comparing to the other high-risk cells, and resources are not sent to cell 52. 


Optimal Obj 1
\begin{tabular}{|l|l|l|l|l|}
\hline 27 & 28 & 29 & 30 & 31 \\
\hline 35 & 36 & 37 & 38 & 39 \\
\hline 43 & 44 & 45 & 46 & 47 \\
\hline 51 & 52 & 53 & 54 & 55 \\
\hline 59 & 60 & 61 & 62 & 63 \\
\hline
\end{tabular}

Optimal Obj2

\begin{tabular}{|l|l|l|l|l|}
\hline 27 & 28 & 29 & 30 & 31 \\
\hline 35 & 36 & 37 & 38 & 39 \\
\hline 43 & 44 & 45 & 46 & 47 \\
\hline 51 & 52 & 53 & 54 & 55 \\
\hline 59 & 60 & 61 & 62 & 63 \\
\hline
\end{tabular}

Burnt cell

Treated cell

High-risk cell

$\mathrm{t}=1$\begin{tabular}{|l|l|l|l|l|}
\hline 27 & 28 & 29 & 30 & 31 \\
\hline 35 & 36 & 37 & 38 & 39 \\
\hline 43 & 44 & 45 & 46 & 47 \\
\hline 51 & 52 & 53 & 54 & 55 \\
\hline 59 & 60 & 61 & 62 & 63 \\
\hline
\end{tabular}

\begin{tabular}{|l|l|l|l|l|}
\hline 27 & 28 & 29 & 30 & 31 \\
\hline 35 & 36 & 37 & 38 & 39 \\
\hline 43 & 44 & 45 & 46 & 47 \\
\hline 51 & 52 & 53 & 54 & 55 \\
\hline 59 & 60 & 61 & 62 & 63 \\
\hline
\end{tabular}

Obj1: Minimizing residents at risk.

Obj2: Minimizing total cost and property loss

$\mathrm{t}=2$\begin{tabular}{|c|c|c|c|c|}
\hline 27 & 28 & 29 & 30 & 31 \\
\hline 35 & 36 & 37 & 38 & 39 \\
\hline 43 & 44 & 45 & 46 & 47 \\
\hline 51 & 52 & 53 & 54 & 55 \\
\hline 59 & 60 & 61 & 62 & 63 \\
\hline
\end{tabular}

\begin{tabular}{|l|l|l|l|l|}
\hline 27 & 28 & 29 & 30 & 31 \\
\hline 35 & 36 & 37 & 38 & 39 \\
\hline 43 & 44 & 45 & 46 & 47 \\
\hline 51 & 52 & 53 & 54 & 55 \\
\hline 59 & 60 & 61 & 62 & 63 \\
\hline
\end{tabular}

$\mathrm{t}=3$\begin{tabular}{|c|c|c|c|c|}
\hline 27 & 28 & 29 & 30 & 31 \\
\hline 35 & 36 & 37 & 38 & 39 \\
\hline 43 & 44 & 45 & 46 & 47 \\
\hline 51 & 52 & 53 & 54 & 55 \\
\hline 59 & 60 & 61 & 62 & 63 \\
\hline
\end{tabular}

\begin{tabular}{|l|l|l|l|l|}
\hline 27 & 28 & 29 & 30 & 31 \\
\hline 35 & 36 & 37 & 38 & 39 \\
\hline 43 & 44 & 45 & 46 & 47 \\
\hline 51 & 52 & 53 & 54 & 55 \\
\hline 59 & 60 & 61 & 62 & 63 \\
\hline
\end{tabular}

Fig. 10. Fire spread process comparison of different single-objective models in $\omega 24$.

Table 10 shows the different first stage decisions in the optimal solutions of the two single-objective models separately. The single-objective model of minimizing residents at risk only considers the total number of residents in high-risk cells, and the first stage 
decisions reflect the unimportance of cost. In this condition, additional on-duty resources are hired as many as possible to deal with any potential extreme cases of residents at risk in scenarios. The single-objective model of minimizing total cost and property loss only considers the expenses. In this condition, the first stage decisions show the importance of hiring cost. Thus, less additional on-duty resources are hired to save expenses compared to the other single-objective model.

Table 10

First Stage Decision Comparison of Single-Objective Models

\begin{tabular}{|c|c|c|}
\hline & $\begin{array}{c}\text { Obj1: } \\
\text { Minimizing residents at risk }\end{array}$ & $\begin{array}{c}\text { Obj2: } \\
\text { Minimizing total cost and } \\
\text { property loss }\end{array}$ \\
\hline \multirow{7}{*}{ First stage decision } & $s_{k 0 i 4}=2$ & \\
& $s_{k 2 i 3}=1$ & $s_{k 0 i 3}=2$ \\
& $s_{k 4 i 3}=2$ & $s_{k 2 i 4}=1$ \\
& $s_{k 5 i 4}=1$ & $s_{k 6 i 4}=1$ \\
& $s_{k 6 i 4}=1$ & $s_{k 7 i 4}=1$ \\
& $s_{k 7 i 3}=1$ & $s_{k 9 i 3}=1$ \\
& $s_{k 11 i 4}=1$ & $s_{k 11 i 3}=1$ \\
& $s_{k 13 i 3}=1$ & $s_{k 13 i 3}=1$ \\
\hline
\end{tabular}

\subsubsection{Two-objective model}

When both objective functions are considered, the optimal solution to this case study is found using the goal programming technique. The goal values for each objective function are determined by two single objective models. Then the goals for the first objective function and the second objective function can be set as 1408 and $\$ 88,129,615$ respectively. In this case, priority is set as 0.9 for the first objective function and 0.1 for the second objective function after the normalization of both objective functions, since residents' safety always has a higher priority than properties in real life. 
Table 11 and Fig. 11 show the solution to the model which considering both objective functions. Within the 32 scenarios with varying wind directions and fire speed, there are only two extreme fire speed scenarios, scenarios 0 which has a fire spread speed of 4 chains per hour in northwest wind and scenario 24 which has a fire spread speed of 36 chains per hour in northwest wind, are shown in Table 11 and Fig. 11.

Resource preparation and allocation results of this case are shown in Table 11. The fire in this case study involves high population density areas in several scenarios which have a high loss potential. Thus, initial decisions are found to be set up of more on-duty firefighters in stations which have enough capacity. 4-person engine groups need to be hired in Stations 0, 6, 9, 11, 13 and 5-person engine groups need to be hired in Stations 2, 7, and 13 .

The second stage decisions include resource allocation plans after a fire breaks out with specific direction and speed. In scenario 0 with slow fire spread rate, the fire is found to be fully contained with three local on-duty resources which are allocated in period 0 . In scenario 24 with rapid-fire, all the local on-duty resources need to be sent to cell 28 in period 0 due to the higher population density and land value. However, these local on-duty resources are found to be not enough to cover all high-risk cells. During period 1, period 2 and period 3, the fire keeps expanding, and more local resources and non-local resources need to be assigned to high-risk areas. In period 3, the fire is found to be under control with the efforts of both local and nonlocal resources. 
Table 11

Resource Preparation and Allocation Results in Two Selected Scenarios

\begin{tabular}{|c|c|c|c|c|}
\hline First stage decision & \multicolumn{2}{|c|}{$\begin{array}{l}s_{k 0 i 3}=2 \\
s_{k 2 i 4}=1 \\
s_{k 6 i 3}=1 \\
s_{k 7 i 4}=1\end{array}$} & \multicolumn{2}{|c|}{$\begin{array}{c}s_{k 9 i 3}=1 \\
s_{k 11 i 3}=1 \\
s_{k 13 i 4}=1\end{array}$} \\
\hline \multirow[b]{2}{*}{$\begin{array}{c}\text { Second stage } \\
\text { decision of } \\
\text { scenario } 0 \\
\text { (Northwest wind } \\
\text { lead to } 4 \text { chains per } \\
\text { hour fire spread } \\
\text { speed) }\end{array}$} & to & $\mathrm{t} 1$ & $\mathrm{t} 2$ & $\mathrm{t} 3$ \\
\hline & $\begin{array}{l}x_{k 2 i 2 \alpha 36 t 0}^{\omega 0}=1 \\
x_{k 2 i 4 \alpha 28 t 0}^{\omega 0}=1 \\
x_{k 7 i 4 \alpha 35 t 0}^{\omega 0}=1\end{array}$ & & & \\
\hline & to & $\mathrm{t} 1$ & $\mathrm{t} 2$ & $\mathrm{t} 3$ \\
\hline $\begin{array}{c}\text { Second stage } \\
\text { decision of } \\
\text { scenario } 24 \\
\text { (Northwest wind } \\
\text { lead to } 36 \text { chains } \\
\text { per hour fire spread } \\
\text { speed) }\end{array}$ & 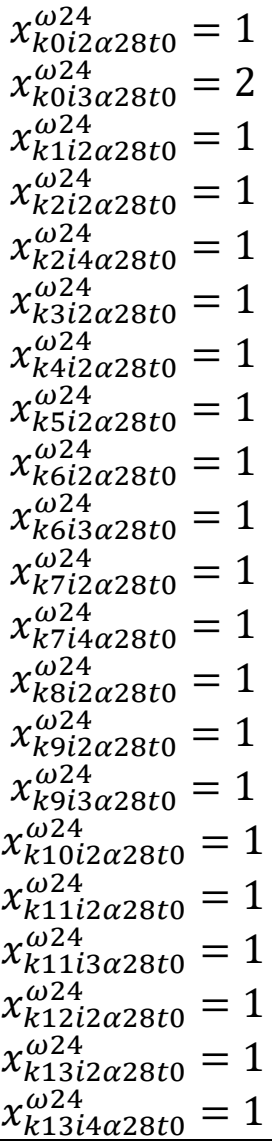 & $\begin{array}{c}y_{k 4 i 4 \alpha 37 t 1}^{\omega 24}=1 \\
y_{k 5 i 4 \alpha 37 t 1}^{\omega 24}=1 \\
y_{k 14 i 5 \alpha 37 t 1}^{\omega 24}=8 \\
z_{l 0 i 4 \alpha 37 t 1}^{\omega 24}=8\end{array}$ & $\begin{array}{l}y_{k 4 i 3 \alpha 52 t 2}^{\omega 24}=1 \\
z_{l 1 i 4 \alpha 46 t 2}^{\omega 24}=15 \\
z_{l 1 i 4 \alpha 51 t 2}^{\omega 24}=15 \\
z_{l 1 i 4 \alpha 52 t 2}^{\omega 24}=14 \\
z_{l 1 i 4 \alpha 53 t 2}^{\omega 24}=15\end{array}$ & $\begin{aligned} z_{l 1 i 4 \alpha 55 t 3}^{\omega 24} & =11 \\
z_{l 2 i 5 \alpha 555 t 3}^{\omega 24} & =3 \\
z_{l 2 i 5 \alpha 62 t 3}^{\omega 24} & =6 \\
z_{l 2 i 5 \alpha 63 t 3}^{\omega 24} & =6 \\
z_{l 2 i 6 \alpha 55 t 3}^{\omega 24} & =1 \\
z_{l 2 i 6 \alpha 662 t 3}^{\omega 24} & =6 \\
z_{l 2 i 6 \alpha 63 t 3}^{\omega 24} & =6\end{aligned}$ \\
\hline $\begin{array}{c}\text { The result of } \\
\text { objective functions }\end{array}$ & $\begin{array}{r}O b j \\
\text { obj2 }=\$ 9 .\end{array}$ & $\begin{array}{l}=1408 \text { Numb } \\
2805 \times 10^{7} \\
\text { containment plus }\end{array}$ & $\begin{array}{l}\text { er of residents at } \\
\text { tal cost of prepar } \\
\text { property losses) }\end{array}$ & $\begin{array}{l}\text { risk) } \\
\text { tion and fire }\end{array}$ \\
\hline
\end{tabular}




$\mathrm{t}=0$\begin{tabular}{|l|l|l|l|l|}
\hline 27 & 28 & 29 & 30 & 31 \\
\hline 35 & 36 & 37 & 38 & 39 \\
\hline 43 & 44 & 45 & 46 & 47 \\
\hline 51 & 52 & 53 & 54 & 55 \\
\hline 59 & 60 & 61 & 62 & 63 \\
\hline
\end{tabular}

\begin{tabular}{|l|l|l|l|l|}
\hline 27 & 28 & 29 & 30 & 31 \\
\hline 35 & 36 & 37 & 38 & 39 \\
\hline 43 & 44 & 45 & 46 & 47 \\
\hline 51 & 52 & 53 & 54 & 55 \\
\hline 59 & 60 & 61 & 62 & 63 \\
\hline
\end{tabular}

Burnt cell Treated cell High-risk cell

$\mathrm{t}=1$\begin{tabular}{|l|l|l|l|l|}
\hline 27 & 28 & 29 & 30 & 31 \\
\hline 35 & 36 & 37 & 38 & 39 \\
\hline 43 & 44 & 45 & 46 & 47 \\
\hline 51 & 52 & 53 & 54 & 55 \\
\hline 59 & 60 & 61 & 62 & 63 \\
\hline
\end{tabular}

\begin{tabular}{|l|l|l|l|l|}
\hline 27 & 28 & 29 & 30 & 31 \\
\hline 35 & 36 & 37 & 38 & 39 \\
\hline 43 & 44 & 45 & 46 & 47 \\
\hline 51 & 52 & 53 & 54 & 55 \\
\hline 59 & 60 & 61 & 62 & 63 \\
\hline
\end{tabular}

$\omega 0$ : Scenario in northwest wind, fire spread speed is 4 chains per hour, cell size is 24 chains.

$\omega 24$ : Scenario in northwest wind, fire spread speed is 36 chains per hour, cell size is 216 chains.

$\mathrm{t}=2$\begin{tabular}{|l|l|l|l|l|}
\hline 27 & 28 & 29 & 30 & 31 \\
\hline 35 & 36 & 37 & 38 & 39 \\
\hline 43 & 44 & 45 & 46 & 47 \\
\hline 51 & 52 & 53 & 54 & 55 \\
\hline 59 & 60 & 61 & 62 & 63 \\
\hline
\end{tabular}

\begin{tabular}{|l|l|l|l|l|}
\hline 27 & 28 & 29 & 30 & 31 \\
\hline 35 & 36 & 37 & 38 & 39 \\
\hline 43 & 44 & 45 & 46 & 47 \\
\hline 51 & 52 & 53 & 54 & 55 \\
\hline 59 & 60 & 61 & 62 & 63 \\
\hline
\end{tabular}

$\mathrm{t}=3$\begin{tabular}{|l|l|l|l|l|}
\hline 27 & 28 & 29 & 30 & 31 \\
\hline 35 & 36 & 37 & 38 & 39 \\
\hline 43 & 44 & 45 & 46 & 47 \\
\hline 51 & 52 & 53 & 54 & 55 \\
\hline 59 & 60 & 61 & 62 & 63 \\
\hline
\end{tabular}

\begin{tabular}{|l|l|l|l|l|}
\hline 27 & 28 & 29 & 30 & 31 \\
\hline 35 & 36 & 37 & 38 & 39 \\
\hline 43 & 44 & 45 & 46 & 47 \\
\hline 51 & 52 & 53 & 54 & 55 \\
\hline 59 & 60 & 61 & 62 & 63 \\
\hline
\end{tabular}

Fig. 11. Cell conditions in two selected scenarios.

Results of cell conditions are shown in Fig. 11. Fig. 11 shows only the partial areas of 64 cells that are involved in these two fire spread scenarios. In scenario 0 , the weak 
wind coming from the northwest direction leads to slow fire spreading to the southeast direction, and the cell size is 24 chains. Then, initial high-risk cells are determined as cells 28,35 , and 36 . On-duty resources are selected and sent to these three cells, and no more resources are needed to contain the fire. In scenario 24, the extreme wind coming from the northwest direction leads to fast fire spreading to southeast direction, and initial high-risk cells are determined as 28,35 and 36 . However, compared with the one in scenario 0 , size of each cell is much larger, which is 216 chains due to "one cell per period" principle explained before. In period 0 , on-duty resources are found to be insufficient for full containment, and they are sent to cell 28 which has the highest number of residents and the highest land value. In period 1, cell 35 and cell 36 have been burnt, and new high-risk cells are determined. Like period 0 , available resources are sent to the most urgent cell, which is cell 37 . By period 3, all the utilized resources are found to be sufficient to treat all the high-risk cells due to the arrival of a large number of nonlocal resources.

The optimal solution for this case study is achieved when $\operatorname{Obj} 1=1408$ and Obj2 $=\$ 90.2785$ million. The optimal solution shows that the first objective function has fully achieved its goal.

To check the Pareto efficiency of this solution, an integer goal programming Pareto efficiency detection technique developed by Tamiz, Mirrazavi, and Jones is applied (Tamiz, Mirrazavi, \& Jones, 1998). Based on their work, the new achievement function is considered as equation (37):

$\max \left\{P_{1} \frac{d_{1}^{-}}{N_{1}}+P_{2} \frac{d_{2}^{-}}{N_{2}}\right\}$ 
The new model is infeasible, i.e. no points can be found for this new achievement function, which proves that no other solution dominating the current optimal solution can be found in the original feasible region. Thus, the solution obtained above is Pareto efficient.

\subsubsection{Computational experiments}

In this section, sensitivity analysis results by changing $P_{1}, P_{2}, G_{1}, G_{2}$ are presented. In these computational experiments, objective functions have been normalized in order to evaluate the impact of $P_{1}$ and $P_{2} . P_{1}$ and $P_{2}$ are chosen between 0 and 1 to show the importance percentages of both objective functions. Optimal objective function values of the individual problems with single objectives are the best values that the model can achieve. Thus, goal values are initially set to individual objective function values to tighten the goal. Then, goal values are increased to relax the goals. When importance factors are fixed and goal values are varied, the results show its sensitivity to goal values. When goal values are fixed and importance factors are varied, the results show its sensitivity to importance factors.

\subsubsection{Experiments with varied priorities}

Table 12 shows the experiments results with $G_{1}=1408, G_{2}=\$ 88.13$ million. These experiments have the same goal value while the priority factors are varied. In this set of experiments, as the first objective function becomes less important, its solution becomes worse while the second objective function's solution keep improving until the goal value $\$ 88.13$ million is fully achieved. 
Table 12

Computational Experiments Result with $G_{1}=1408$ and $G_{2}=88.13 \mathrm{M}$

\begin{tabular}{|c|c|c|c|c|c|c|c|}
\hline No. & $P_{1}$ & $P_{2}$ & $O b j_{1}$ & $O_{b j}(\$)$ & Dev1 & Dev2 (\$) & Time(s) \\
\hline 1 & 0.999 & 0.001 & 1408 & $93.11 \mathrm{M}$ & 0 & $4.98 \mathrm{M}$ & 154 \\
\hline 2 & 0.99 & 0.01 & 1408 & $90.29 \mathrm{M}$ & 0 & $2.16 \mathrm{M}$ & 114 \\
\hline 3 & 0.9 & 0.1 & 1408 & $90.28 \mathrm{M}$ & 0 & $2.15 \mathrm{M}$ & 123 \\
\hline 4 & 0.5 & 0.5 & 1411 & $88.96 \mathrm{M}$ & 3 & $0.83 \mathrm{M}$ & 176 \\
\hline 5 & 0.1 & 0.9 & 1444 & $88.13 \mathrm{M}$ & 36 & 0 & 147 \\
\hline 6 & 0.01 & 0.99 & 1444 & $88.13 \mathrm{M}$ & 36 & 0 & 135 \\
\hline 7 & 0.001 & 0.999 & 1444 & $88.13 \mathrm{M}$ & 36 & 0 & 131 \\
\hline
\end{tabular}

2.4.3.2 Experiments with varied goal values

Table 13 shows the experiments results with $P_{1}=0.9, P_{2}=0.1$. These experiments have the same priority factors while goal values varied. In this set of experiments, the first objective function that minimizing at-risk residents is fully achieved when the first goal value is set as the value of 1408 , which is the optimal solution to the single objective model of minimizing residents at risk. Similarly, the second objective function that minimizing total cost is closer to the goal or fully achieved when the second goal value is set as the value of $\$ 88.13$ million, which is the optimal solution to the single objective model of minimizing total cost. When either of objective functions is relaxed by related high goal value, the solution to that corresponding objective function will become worse. When both objective functions are relaxed by very high goal values, solutions to both objective functions are much worse than other experiments in this set. 
Table 13

Computational Experiments Result with $P_{1}=0.9$ and $P_{2}=0.1$

\begin{tabular}{|c|c|c|c|c|c|c|c|}
\hline No. & $G_{1}$ & $G_{2}$ & $\mathrm{Obj}_{1}$ & $\mathrm{Obj}_{2}(\$)$ & $\mathrm{Dev1}$ & $\mathrm{Dev2}(\$)$ & Time(s) \\
\hline 1 & 1408 & $88.13 \mathrm{M}$ & 1408 & $90.28 \mathrm{M}$ & 0 & $2.15 \mathrm{M}$ & 123 \\
\hline 2 & 1408 & $100 \mathrm{M}$ & 1408 & $95.49 \mathrm{M}$ & 0 & $-4.51 \mathrm{M}$ & 109 \\
\hline 3 & 1408 & $150 \mathrm{M}$ & 1408 & $95.50 \mathrm{M}$ & 0 & $-54.50 \mathrm{M}$ & 111 \\
\hline 4 & 1500 & $88.13 \mathrm{M}$ & 1444 & $88.13 \mathrm{M}$ & -56 & 0 & 137 \\
\hline 5 & 1500 & $100 \mathrm{M}$ & 1437 & $99.77 \mathrm{M}$ & -63 & $-0.23 \mathrm{M}$ & 91 \\
\hline 6 & 1500 & $150 \mathrm{M}$ & 1482 & $126.25 \mathrm{M}$ & -18 & $-23.75 \mathrm{M}$ & 85 \\
\hline 7 & 2000 & $88.13 \mathrm{M}$ & 1444 & $88.13 \mathrm{M}$ & -556 & 0 & 130 \\
\hline 8 & 2000 & $100 \mathrm{M}$ & 1499 & $99.53 \mathrm{M}$ & -501 & $-0.47 \mathrm{M}$ & 89 \\
\hline 9 & 2000 & $150 \mathrm{M}$ & 1553 & $130.73 \mathrm{M}$ & -447 & $-19.27 \mathrm{M}$ & 86 \\
\hline
\end{tabular}

\subsubsection{Experiment results analysis}

From the computational experiments, it is seen that both priorities and goal values affect results. When one of the objective functions becomes more critical, the one with higher priority tends to achieve the optimal value while the other one moves towards a worse solution. When one of the goal values is relaxed (increased), the optimal solution produces a worse (increased) value for the related objective function. 


\section{CHAPTER 3}

\section{CONCLUSION}

\subsection{Thesis Contribution}

This thesis presents a new integer stochastic goal programming model to solve the resident evacuation and resource allocation problem for wildfire preparedness and response. The proposed model in this thesis minimizes both the number of residents at risk and total cost of fire containment and property loss. A new approach is explored in this thesis to keep the number of variables constant by increasing the size of grids for the scenarios which have higher fire spread speed. Results show that this stochastic goal programming model can produce efficient solutions to highly comprehensive realistic WUI wildfire problems with considerations on all possible fire scenarios. In each scenario, the fire spread process is influenced by human response actions along with the wind speed. Computational experiments with different priority settings indicate that it is possible to find efficient solutions by considering a trade-off between the two objective functions.

Goal programming is used to solve this multi-objective problem. A disadvantage of goal programming methodology is that the decision maker must make assumptions to goals and their priorities, which are difficult to determine. However, it is a relatively simple method in that only a few additional variables are required to solve multi-objective problems. The impact of the priority parameters on the optimal solution can be investigated with computational experiments. For complex real-world problems 
such as WUI wildfire preparedness and containment, goal programming ensures that a solution can be found in a short time and it is easy to understand.

\subsection{Limitation and Future Direction}

In the practical application of this model, the effectiveness of the produced solution is highly related to the accuracy of the collected data. However, in large-scale real-life problems, data cannot be simply collected from published resources. For example, land values and residents in each cell are key parameters for resource allocation decisions, while these values are gathered from published data in this model assuming a uniform distribution within a cell. A more accurate data acquisition and conversion module is needed to be developed to apply this fire containment model.

An important assumption in this model is that wind speed and direction do not change once a fire breaks out, which is a reasonable assumption for most of the relatively stable situations where fires are contained within a few hours or at most in the first few days, following the assumption of predictable seasonal wind behavior in a known topology. But in some exceptional cases, the wind may suddenly change before containment or fire suppression lasts for several weeks, so that fire spread direction may change after periods. In those cases, the problem presented here becomes a three-stage, four-stage or even ten-stage stochastic programming problem. Then the problem formulation needs to be extended to reflect changing scenarios. However, when dealing with real problems, wind conditions and the fire spread direction usually behave with much more complexity than the assumptions in this model. The model in this thesis can provide solutions in a system level by following the assumed basic rules. More detailed 
plans can be available by combining this model with a precise wind prediction model or fire behavior prediction model.

Another assumption in this model is that once resource allocation decisions are made, all the allocated resources stay in a specific area until the fire is fully contained. If firefighting resources can decide that the fire will not spread in their current area and the fire keep spreading in other areas, they may be reallocated.

Fuel management focusing on specific high-risk areas to reduce fire risk and magnitude is also a critical part of wildfire preparation. Thus, a more detailed model which considers both fuel management and fire suppression could be developed in the future. Furthermore, the model presented in this thesis has the limiting assumption of homogenous geographical structure in each cell, which can only provide a framework for more realistic applications with heterogeneous geographic areas. More realistic models could be developed, incorporating a mathematical model with a geographic information system software.

In addition, disaster response including wildfire containment is a problem with high complexity. Resource allocation and resident evacuation are also greatly influenced by traffic conditions and timing of the fire. Effects of a WUI wildfire are usually large besides threat to life, wildlife and property in the fire area. Smoke and its effects on residents' and wild animals' health also should be considered. 


\section{REFERENCES}

Arrubla, J. A., Ntaimo, L., \& Stripling, C. (2014). Wildfire initial response planning using probabilistically constrained stochastic integer programming. International Journal of Wildland Fire, 23(6), 825-838. doi: 10.1071/WF13204

Birge, J. R., \& Louveaux, F. (2011). Introduction to stochastic programming. New York: Springer. doi: 10.1007/978-1-4614-0237-4

CAL FIRE. (2004, May). Cooperative emergency response. Retrieved from CAL FIRE http://calfire.ca.gov/communications/downloads/fact_sheets/CoopResponse.pdf

CAL FIRE. (2017, October 30). California statewide fire summary. Retrieved from CAL FIRE http://calfire.ca.gov/communications/communications_StatewideFireSummary

CAL FIRE. (2018, December 11). Camp fire incident information. Retrieved from CAL FIRE http://www.fire.ca.gov/current_incidents/incidentdetails/Index/2277

CAL FIRE. (2018). The fire and resource assessment program. Retrieved from FRAP Maps http://frap.fire.ca.gov/data/frapgismaps/pdfs/fmod_map.pdf

CAL FIRE. (2018, March 28). Thomas fire incident information. Retrieved from CAL FIRE http://cdfdata.fire.ca.gov/incidents/incidents_details_info?incident_id=1922

California Governor's Office of Emergency Services. (2014, December). California fire service and rescue emergency mutual aid system mutual aid plan. Retrieved from California Governor's Office of Emergency Services http://www.caloes.ca.gov/FireRescueSite/

Calkin, D. E., Cohen, J. D., Finney, M. A., \& Thompson, M. P. (2014). How risk management can prevent future wildfire disasters in the wildland-urban interface. PNAS, 111(2), 746-751. doi: 10.1073/pnas.1315088111

Cova, T. J., Dennison, P. E., \& Kim, T. H. (2005). Setting wildfire evacuation trigger points using fire spread modeling and GIS. Transactions in GIS, 9(4), 603-617. doi: 10.1111/j.1467-9671.2005.00237.x

Donovan, G. H., \& Rideout, D. B. (2003). An integer programming model to optimize resource allocation for wildfire containment. Forest Science, 49(2), 331-335.

Google. (2018, May). Google maps. Retrieved from Google https://www.google.com/maps/@37.2533529,-121.8479354,15z 
Graham, S. E., \& Pike, R. J. (1998). Slope map of Santa Clara County, California: A digital database. Retrieved from USGS Publications Warehouse https://pubs.usgs.gov/of/1998/of98-766/of98-766_5h.pdf

Gurobi Optimization, L. (2018). Gurobi optimizer reference manual. Retrieved from http://www.gurobi.com

Hu, X., \& Ntaimo, L. (2009). Integrated simulation and optimization for wildfire containment. ACM Transactions on Modeling and Computer Simulation, 19(4), 1-29. doi: 10.1145/1596519.1596524

IOSWT. (2004). Fireline handbook. Boise: National Wildfire Coordinating Group.

Jin, Y., Goulden, M. L., Faivre, N., Veravrbeke, S., Sun, F., Hall, A., . . Randerson, J. T. (2015). Identification of two distinct fire regimes in Southern California: implications for economic impact and future change. Environmental Research Letters, 10(9), 1-12. doi: 10.1088/1748-9326/10/9/094005

Li, D., Cova, T. J., \& Dennison, P. E. (2015). A household-level approach to staging wildfire evacuation warnings using trigger modeling. Computers Environment and Urban Systems, 54, 56-67. doi: 10.1016/j.compenvurbsys.2015.05.008

Minas, J. P., Hearne, J. W., \& Martell, D. L. (2014). A spatial optimization model for multi-period landscape level fuel management to mitigate wildfire impacts.

European Journal of Operational Research, 232(2), 412-422. doi: 10.1016/j.ejor.2013.07.026

Minas, J. P., Hearne, J. W., \& Martell, D. L. (2015). An integrated optimization model for fuel management and fire suppression preparedness planning. Annals of Operations Research, 232(1), 201-215.

NWCG. (2018, May 14). Reference fuel moisture. Retrieved from The National Wildfire Coordinating Group https://www.nwcg.gov/sites/default/files/products/table_a_reference_fuel_moistur e.pdf

NWSA. (2013, October). Cost analysis: Wildland fire crews and engines. Retrieved from National Wildfire Suppression Association http://www.nwsa.us/Websites/nwsa/images/2013_NWSA_COST_REPORT_FIN AL_11-18-13.pdf

Pacific Northwest Wildfire Coordinating Group. (2017, May 22). PNWCG federal incident business management guidelines. Retrieved from U.S. Forest Service https://www.fs.fed.us/r6/fire/incident-business/documents/40-current_PNW_IBM OpGuidelines_final.pdf 
Paveglio, T., Prato, T., Dalenberg, D., \& Venn, T. (2014). Understanding evacuation preferences and wildfire mitigations among Northwest Montana residents. International Journal of Wildland Fire, 23(3), 435-444. doi: 10.1071/WF13057

Rashidi, E., Medal, H., Gordon, J., Grala, R., \& Varner, M. (2017). A maximal covering location-based model for analyzing the vulnerability of landscapes to wildfires: Assessing the worst-case scenario. European Journal of Operational Research, 258(3), 1095-1105. doi: 10.1016/j.ejor.2016.08.074

SCCFD. (2015, January). Business plan. Retrieved from Santa Clara County Fire Department

http://www.sccfd.org/images/documents/key_reports_documents/SCCFDBusiness Plan20152019compressed.pdf

SCCFD. (2017). Santa Clara County Fire Department 2017 annual report. Los Gatos: Santa Clara County Fire Department.

Schniederjans, M. J. (1984). Linear goal programming. Princeton: Petrocelli Books.

Southwest Coordination Center. (2004). Agency administrator guide 2004. Retrieved from National Geographic Area Coordination Centers https://gacc.nifc.gov/swcc/management_admin/Agency_Administrator/AA_Guide lines/pdf_files/ch5.pdf

Tamiz, M., Jones, D., \& Romero, C. (1998). Goal programming for decision making: An overview of the current state-of-the-art. European Journal of Operational Research, 111(3), 569-581. doi: 10.1016/S0377-2217(97)00317-2

Tamiz, M., Mirrazavi, S., \& Jones, D. (1998). Extensions of Pareto efficiency analysis to integer goal programming. Omega, 27(2), 179-188. doi:

$10.1016 / \mathrm{S} 0305-0483(98) 00038-3$

The Weather Company. (2018, May 14). Weather history for KSJC. Retrieved from Weather Underground https://www.wunderground.com/history/airport/KSJC/

U.S. Department of Commerce. (2018). Quick facts for states and counties. Retrieved from United States Census Bureau https://www.census.gov/quickfacts/fact/table/US/PST045217

USDL. (2018, March 30). Occupational employment and wages, May 2017. Retrieved from Bureau Of Labor Statistics https://www.bls.gov/oes/current/oes332011.htm\#st 
Yan, H. (2017, December 26). The wildfires in California just keep shattering records this year. Retrieved from CNN https://www.cnn.com/2017/12/18/us/california-fires/index.html

Zhan, S., \& Liu, N. (2011). A multi-objective stochastic programming model for emergency logistics based on goal programming. 2011 Fourth International Joint Conference on Computational Sciences and Optimization, 640-644. doi: 10.1109/CSO.2011.44

Zillow. (2018). Map of homes. Retrieved from Zillow https://www.zillow.com/homes/ 